\title{
Multi-Decadal Trend and Decadal Variability of the Regional Sea Level over the Indian Ocean since the 1960s: Roles of Climate Modes and External Forcing
}

\author{
Weiqing Han ${ }^{1, *(\mathbb{D})}$, Detlef Stammer ${ }^{2}$, Gerald A. Meehl ${ }^{3}$, Aixue $\mathrm{Hu}^{3}{ }^{(\mathbb{D}}$, Frank Sienz ${ }^{4}$ and \\ Lei Zhang ${ }^{1}$ \\ 1 Department of Atmospheric and Oceanic Sciences, University of Colorado, UCB 311, Boulder, CO 80309, \\ USA; lei.zhang-4@colorado.edu \\ 2 Center for Earth System Research and Sustainability, University of Hamburg, 20146 Hamburg, Germany; \\ detlef.stammer@uni-hamburg.de \\ 3 Climate and Global Division, National Center for Atmospheric Research, Boulder, CO 80305, USA; \\ meehl@ucar.edu (G.A.M.); ahu@ucar.edu (A.H.) \\ 4 The Max-Planck-Institute for Meteorology, 20146 Hamburg, Germany; frank.sienz@mpimet.mpg.de \\ * Correspondence: whan@colorado.edu; Tel.: +1-303-735-3079
}

Received: 1 May 2018; Accepted: 6 June 2018; Published: 8 June 2018

\begin{abstract}
Previous studies suggest that anthropogenic warming has affected the multi-decadal trend patterns of sea level over the Indian Ocean (IO). This effect, however, has not been quantified. Using observational datasets combined with large ensemble experiments from two climate models, this paper assesses the effects of natural internal variability versus external forcing on the observed, multi-decadal trend pattern and the decadal sea level anomaly (SLA) of the IO since the 1960s. Because the global mean sea level rise (SLR), which results largely from external forcing, has been removed before the examination, the paper focuses on the regionally uneven distribution of trend and SLA. The impacts of climate modes are quantified using a Bayesian Dynamic Linear Model. For the regional trend pattern of 1958-2005, the effects of internal variability dominate external forcing. Over the Seychelles area where sea-level variations obtain the maximum, internal variability (external forcing) contributes $81 \%(19 \pm 2.4 \%)$ of the observed trend. For decadal SLA, internal variability is the predominant cause, with a standard deviation (STD) ratio of externally forced/observed SLA being $18 \pm 17 \%$ over Seychelles and $17 \pm 11 \%$ near the Indonesian Throughflow (ITF) area. Climate modes account for most observed SLA during boreal winter, with the total effects of decadal ENSO, Indian Ocean Dipole (IOD), and monsoon accounting for $78-86 \%$ of the observed STD near the Seychelles region, ITF area, and coasts of Sumatra and the Bay of Bengal. During summer, climate modes explain $95 \%$ of observed STD near the ITF but only $58-67 \%$ in other regions. Decadal ENSO dominates the SLA in the south tropical IO for both seasons and near the coasts of Sumatra and the Bay during winter. Decadal IOD and monsoon, however, control the coastal SLA during summer. Remote and local winds over the IO are the main drivers for decadal SLA, while the Pacific influence via the ITF is strong mainly in the southeast basin.
\end{abstract}

Keywords: regional sea level; multi-decadal trend; decadal variability; climate mode; internal variability; external forcing; Indian Ocean

\section{Introduction}

Many low-lying coastal areas and island nations of the Indian Ocean (IO) are highly vulnerable to sea level rise (SLR) as they harbor one-third of the world's populations that are heavily populated by developing countries, which have poor disaster management resources [1]. The rapid population 
growth will further increase their vulnerability in the future [2]. Consequently, there is a strong societal demand for improved projections of future SLR and decadal predictions of sea-level variations over the IO region $[1,3,4]$. Yet, our understanding of IO regional, decadal sea-level variations and their major drivers is very limited, whereas this understanding is instrumental for reliable decadal predictions and uncertainty quantifications of future SLR projections. This paper aims to assess the effects of natural internal variability, particularly climate modes, and external forcing (natural plus anthropogenic) on the observed IO decadal sea level variability and multi-decadal trend pattern, with global mean SLR (due largely to external forcing) being removed. Here, "decadal variability" is collectively referred to as variations from one to a few decades.

\subsection{Background}

Regional sea level variability can be induced by various factors: changes in atmospheric and oceanic circulations, large-scale deformation of ocean basins, the variation of Earth's gravity field, and local land movement [4-6]. Among these factors, changes in atmospheric and oceanic circulations are shown to be the major cause for basin-wide spatial patterns of contemporary decadal sea-level variations [5]. Over the tropical IO, multi-decadal trends of sea level since the 1960s exhibit a distinct spatial pattern, with the falling sea level occurring in the southwest basin where the thermocline ridge and the Seychelles Islands are located [7-10] but rising sea level elsewhere [11-13]. Experiments using ocean general circulation models (OGCMs) show that the changing surface wind is the major force for this basin-wide sea level pattern [11], and variations of the Indonesian Throughflow (ITF) may have also contributed to the thermocline cooling [14] and, thus, the sea level fall in the tropical southwest IO [15]. While the multi-decadal trend of the surface wind may be largely associated with natural internal variability, experiments using an atmospheric GCM suggest that the changing wind could also be partly forced by IO warming [11], which was attributed primarily to anthropogenic greenhouse gas (GHG) forcing [16,17]. What are the relative roles of natural internal climate variability versus external forcing (for example, solar, volcano, GHG) in causing the multi-decadal trend pattern of sea level over the IO? This is an important science question remaining to be answered.

Overlying the multi-decadal trend, satellite observations show large decadal variations of basin-wide sea level patterns in recent decades, with reversing trends between 1993-2000 and 2000-2006 [18]. Over the North IO, the sea level experienced basin-wide falls from 1993-2003 but sharp rises from 2004-2013 [19,20]. Both observational analyses and OGCM experiments suggest that the surface wind over the IO is the primary cause for the observed decadal sea level variability [19-22], with the ITF making significant contributions primarily in the southeast tropical IO [21,23]. Thermosteric sea level is the primary contributor $[22,24,25]$, with the halosteric sea level having apparent influence in some regions [22], such as the tropical southeast IO [26]. While surface wind associated with natural internal variability is suggested to be the major cause for decadal sea level variability [5,27], the effect of external forcing on regional, decadal sea-level variations over the IO remains unknown.

To what extent is the IO decadal sea level variability associated with internal climate modes? To answer this question, $\mathrm{Li}$ and Han performed a suite of OGCM experiments to assess the forcing by surface wind stress associated with climate modes, stochastic wind, and buoyancy flux from 1948-2012 [28]. To extract the wind stress signals associated with climate modes, they first performed multiple linear regression onto the monthly Multivariate ENSO Index (MEI) and IO dipole (IOD) mode index (DMI) [29,30], using NCEP reanalysis wind and HadISST sea surface temperature (SST) data. Then, they removed the ENSO- and IOD-associated signals from the surface wind and SST and applied singular value decomposition (SVD) to obtain the wind-SST covariance for the residuals. The sum of the wind stress anomalies associated with ENSO, IOD, and the leading 7 SVD modes of the residuals represent the total effect of all climate modes. Their results suggested that the decadal sea level variability north of $20^{\circ} \mathrm{S}$ is primarily induced by wind stress associated with climate modes, with the largest variability occurring in the thermocline ridge region. 
To assess the effect of an individual climate mode—-the Pacific Decadal Oscillation (PDO)—on Indo-Pacific decadal sea level variability, Frankcombe et al. obtained the multiple linear regression patterns by regressing the reanalysis and OGCM-simulated sea level onto the PDO index [31]. Their results showed that the PDO is moderately correlated with decadal sea level variability in some regions of the tropical IO, and the regression coefficients are much weaker than those of ENSO and IOD on interannual timescales, and the association of sea level with the Southern Annular Mode (SAM) is weak.

Note that both these studies $[28,31]$ used the multiple linear regression approach, which assumes stationary relationships (that is, constant regression coefficients) between climate modes and their associated fields (for example, surface winds and sea level). In the real climate system, however, their relationships are often non-stationary and evolve with time. For instance, it has been shown that the influence of El Niño on the subtropical northwest Pacific climate has significantly increased after the 1970s [32]; decadal variability of Indian summer monsoon convection is more important since the 1990s compared to prior decades in determining the decadal variability of the Indian Walker Cell [33]. While strong El Niño events generally induce a weaker Indian summer monsoon and thus, severe drought, some strong El Niño events correspond to normal monsoons [34]. The conventional multiple linear regression cannot capture these changing relationships, which is a limitation in its application (see Section 2.4 for details). Moreover, the relative importance of climate modes in determining decadal sea-level variations in different regions of the IO is unknown, and the seasonality of their impact remains unclear [28]. Yet, understanding the impacts of climate modes has important implications for climate predictions, because internal climate modes with physical bases, such as IOD and ENSO, possess predictability and can be predicted with positive skills two or three seasons in advance [35,36], even though no decadal-scale predictability of ENSO behavior was found in a long-control simulation of a global climate model [37].

\subsection{Present Research}

The goal of this research is to quantify the effects of internal climate modes and external forcing on the observed IO regional, uneven distribution of the sea level trend and decadal variability (with global mean SLR removed). To achieve the goal, we first analyze the observed patterns of multi-decadal trend and decadal sea level variability (departure from the global mean), and then extract the imprints of internal climate modes in the observed sea level and surface winds using a relatively new approach, the Bayesian Dynamic Linear Model (DLM) [38]. The Bayesian DLM can capture the non-stationary impacts of climate modes, which cannot be achieved by the conventional multiple linear regression, referred to as static linear model (SLM) in previous studies $[33,38]$. Comparisons between Bayesian DLM and SLM in assessing the climate modes' impacts on decadal variability of Indian and Pacific Walker Cells reveal that the DLM considerably outperforms SLM in simulating the Walker Cells' variability, and has captured the non-stationary nature of climate modes' impacts over different decades [33]. To examine the effects of external forcing, we analyze the results from large ensemble (LE) experiments of two global climate models and compare them with observational datasets (see Section 2 for more details) because the influence of external forcing is difficult to quantify using observational analysis alone. Our major period of interest is from the 1960s to the present when more reliable ocean-atmosphere datasets are available. Results from this research will contribute to a better understanding of decadal predictions and uncertainties of the externally forced, regional sea level signals over the IO and, therefore, benefit a large fraction of the region's populations.

Here, we focus on decadal-scale variability for two reasons. First, decadal prediction emerges as a pressing priority in climate research due to strong society demands for planning purposes [39-45]. Second, empirical approaches, including the Bayesian DLM, build simultaneous relationships between climate mode indices and sea level variability (Section 2.4), indicating that variations of climate modes are in quasi-equilibrium with variations of sea level. The physical bases for their relationships are that climate modes affect sea level through affecting surface forcing fields (for example, surface 
wind, precipitation) [28-30,36]. While surface wind and rainfall over the IO can respond quickly (a few days) to SST associated with climate modes (for example, ENSO) $[29,30,36]$, variations of sea level are not always in equilibrium with surface wind forcing due to oceanic wave propagations. On decadal timescales, surface wind and sea level over the tropical IO basin are largely in quasi-equilibrium, but this is untrue at inter-annual and shorter timescales (see Section 2.5 for further discussion).

\section{Materials and Methods}

\subsection{Datasets: Sea Level and Surface Wind}

To document the observed multi-decadal trend and decadal variability of IO regional sea level, we analyze monthly sea level data from the ECMWF Ocean Reanalysis System 4 (ORAS4) available for 1958-2015 [46], and from the Simple Ocean Data Assimilation (SODA version 2.2.4) reanalysis available for 1871-2010 [47]. Note that the OGCMs for producing these reanalysis products made the Boussinesq approximation and, thus, implicitly assume the total ocean volume is conserved, even though the global mean temperature is rising and continental ice is melting. Consequently, the global mean SLR is excluded and the regional sea-level variations (both trend pattern and decadal variability) analyzed here are departures from the global mean (that is, the dynamical sea level). The ORAS4 data, however, assimilated the satellite-observed sea level [46], yielding a global mean rising trend since 1993 [48]. Variances of decadal sea level anomaly (SLA) from satellite altimetry are reasonably reproduced by both reanalysis data over the $\mathrm{IO}$, even though there are quantitative differences in some regions [49]. Since the thermosteric sea level is the dominant component of basin-wide decadal SLA (Section 1), the upper $700 \mathrm{~m}$ thermosteric sea level data from the world ocean atlas 2013 (WOA13) for 1955-2015 and from Ishii and Kimoto for 1945-2014 [50,51] are also analyzed. Finally, even though the record is short, the multiple-satellite merged monthly SLA data from the French Archiving, Validation, and Interpolation of Satellite Oceanographic Data (AVISO) project [52,53] for 1993-2015 are also examined.

To help understand the effects of climate-modes-associated surface winds on IO decadal SLA, we also examine the monthly surface winds from the Japan Meteorological Agency 55-yr Reanalysis (JRA55) from 1958-2015 [54]. Han et al. compared various reanalysis wind products, and showed that the decadal variability of the Indian Walker Cell, represented by zonal surface wind of the equatorial IO since the 1960s, and its seasonality are robust to cross-dataset differences, and they agree with the zonal sea level gradient detected by ORAS4 and upper $700 \mathrm{~m}$ thermosteric sea level [33]. The decadal variability and seasonality of the Indian Walker Cell detected by the JRA55 wind also agree with the cross-calibrated multiplatform (CCMP) satellite winds version 1 [55] during their overlapping period [33]. The CCMP monthly winds since 1987, satellite-observed monthly Outgoing Longwave Radiation (OLR) — a proxy of tropical deep convection—available since 1974 [56], and Global Precipitation Climatology Project (GPCP) monthly precipitation available since 1979 [57] are also analyzed.

To isolate decadal signals, a Lanczos lowpass filter [58] with half power at the 8 year period is used. The response curve of the 8 year lowpass filter retains $\sim 90 \%$ of the amplitude at the 10 year period and almost full amplitudes for longer periods, which essentially retains the decadal variability signals with periods of 10 year and longer. Similar lowpass filters have been successfully applied to investigate decadal variability by many existing studies [31,33,59-61].

\subsection{Large Ensemble (LE) Experiment Results from Two Climate Models}

To assess the contribution of external forcing on the regional sea level trend and decadal SLA over the tropical IO, we utilize the recently available LE simulations with all (both natural and anthropogenic) forcing from two global climate models: the National Center for Atmospheric Research (NCAR) community earth system model version 1 (CESM1) [62] and the Max-Planck-Institute 
for meteorology (MPI, Hamburg, Germany) earth system model, an updated version of the same model used in CMIP5 [63]. Monthly data from the 40-member ensemble of CESM1 simulations are available for 1920-2005, and that from the 100-member ensemble of MPI are available for 1850-2005. Their monthly dynamical sea level data are analyzed and the model drifts are removed before the analyses. The 40- and 100-member ensembles are used to assess the effect of external forcing.

Note that the cross-model differences of regional sea level variability are large between the two LE model results, not only for multi-decadal trends but also for decadal SLAs. Consequently, we focus only on analyzing and comparing their SLA magnitudes (for example, variances) rather than their phases, when we estimate the effects of external forcing. Note also that we use the LE experiments only to assess the contribution of external forcing relative to the observed SLAs. Examining and comparing the natural internal variability versus externally forced SLAs in each climate model is beyond the scope of this paper.

\subsection{Datasets for Climate Modes and Other Climate Indices}

To understand the IO decadal sea level variability associated with internal climate modes, we examine the relationships between sea level and ENSO and IOD, the two dominant inter-annual climate modes over the Indo-Pacific basin with evident decadal modulation $[15,27,64,65]$. Note that decadal variability of ENSO, represented by the 8 year low-passed Nino3.4 index and MEI, is highly correlated with the PDO and Inter-decadal Pacific Oscillation (IPO) indices, with Nino3.4-IPO and IPO-PDO correlations both being $~ 0.88$ from 1900-2008 and the IPO-MEI correlation being 0.89 from 1900-2001 [61,66]. Following Han et al. (2017) [33], we use the 8 year low-passed Nino3.4 index to represent the decadal variability of the ENSO or IPO. Hereafter, we refer it to as decadal ENSO. For the IOD, its decadal variability is represented by the 8 year low-passed DMI. Here, we calculate the DMI for each month, whereas the IOD is active only during summer-to-fall and peaks in Sep-Nov [33]. Consequently, the "DMI" here essentially represents the east-west SST gradient during January-May. For convenience, we still refer it to as the IOD. Indices of ENSO and IOD are calculated using monthly HadISST data [67] available since 1870, and then the 8 year low-passed Lanczos filter is applied.

In addition to ENSO and IOD, the decadal variability of monsoon winds over the IO can drive the large variability of IO sea level. Since the strengths of monsoon winds are tied to that of monsoon rainfall over India during boreal summer, the Indian Institute of Tropical Meteorology homogeneous monthly All India Rainfall dataset available from 1871-2014 [68] is used to serve as the monsoon index. Note that the leading Empirical Orthogonal Function (EOF) mode of IO SST (IOSST) is a basin-wide warming/cooling pattern at both inter-annual and decadal timescales [15,61,69]. Because the basin-scale IOSST is primarily induced by ENSO [61,69], its influence is largely imprinted in the ENSO index. Since the 1980s, however, the relationship between decadal ENSO and IOSST has reversed [15,61] due to volcanic eruptions and anthropogenic warming [70,71]. As a result, decadal IOSST has had an active impact on the Pacific trades and sea level during recent decades [61,72]. In this paper, the effect of decadal IOSST, the part that is independent of decadal ENSO, will also be examined using Bayesian DLM (see below).

\subsection{The Bayesian DLM and Partial DLM}

Since the Bayesian DLM and partial DLM have been discussed in detail in Han et al. (2017) [33], here, we only discuss the aspects essential to this paper. The DLM consists of two equations: an "observation equation" shown by Equation (1), and a "state equation" represented by Equation (2):

$$
\begin{gathered}
Y(t)=b_{0}(t)+b_{1}(t) X_{1}(t)+\ldots+b_{M}(t) X_{M}(t)+\varepsilon(t), \quad \varepsilon(t) \sim N(0, V(t)), \\
b_{i}(t)=b_{i}(t-1)+w_{i}(t), \quad w_{i}(t) \sim N\left(0, W_{i}(t)\right) .
\end{gathered}
$$

The observation Equation (1) builds the relationship between predictand $Y$ and predictors $\left(X_{1}\right.$, $\left.\ldots X_{M}\right)$, where $M$ is the number of predictors, and the state Equation (2) controls the dynamical 
evolution of coefficients $b_{i}(i=0,1,2, \ldots M)$. Equation (2) states that the predictive distribution of $b_{i}$ at each time step $t$ (that is, posterior) is updated based on its previous step $t-1$ distribution (that is, prior) and the probability of observations $Y$ conditional on $b_{i}$ at time $t$ (that is, the likelihood) using Bayes theorem [38]. Coefficient $b_{i}(t)$ is obtained by applying Kalman filtering and smoothing, and it measures the "dynamical" (time-evolving) impacts of $X_{i}$ on $Y$, which overcomes the limitation of the constant coefficients of the conventional multiple linear regression. In the above, term $b_{0}(t)$ represents a time-varying intercept whose variability is unexplained by the predictors $X_{i}$, while the $b_{i}$ terms represent the non-stationary influence of $X_{i}$ on $Y ; \varepsilon(t)$ and $w_{i}(t)$ are independent white noises or errors, distributed normally with a mean of 0 and variances of $V(t)$ and $W_{i}(t)$. The choices and calculations for $W_{i}(t)$ and $V(t)$ follow those in Reference [38]. For more details of the Bayesian DLM, please see References [33,38].

Here, predictors $X_{i}$ represent the climate mode indices, and predictand $Y$ represents the SLA. Since the decadal variability of ENSO and IOD are moderately correlated, yet the DLM requires the predictors to be independent, we apply the partial Bayesian DLM to remove the ENSO influence from both the DMI and SLA before we examine the IOD effect. Specifically, using ENSO as the predictor, Equation (1) becomes

$$
S L A(t)=b_{0}(t)+b_{1}(t) E N S O(t)+\varepsilon(t) .
$$

Then, we apply the Bayesian DLM to the residual, $S L A^{\prime}=S L A(t)-b_{1}(t) E N S O(t)$, using DMI and monsoon index (with ENSO signal removed) as predictors:

$$
\operatorname{SLA} A^{\prime}(t)=b_{0}{ }^{\prime}(t)+b_{1}{ }^{\prime}(t) I O D(t)+b_{2}{ }^{\prime}(t) \operatorname{Monsoon}(t)+\varepsilon^{\prime}(t) .
$$

Note that in Equation (4), the monsoon effect on IOD is also removed from the DMI. In addition, the decadal IOSST, which is induced by the external forcing since the 1980s [71], may also influence IO convection, winds and, thus, sea level. To consider this effect, we perform partial Bayesian DLM to the SLA residual,

$$
\operatorname{SLA}^{\prime \prime}(t)=b_{0}{ }^{\prime \prime}(t)+b_{1}{ }^{\prime \prime}(t) \operatorname{IOSST}(t)+\varepsilon^{\prime \prime}(t) .
$$

In Equation (5), residual $S L A^{\prime \prime}(t)=S L A(t)-b_{1}(t) E N S O(t)-b_{1}{ }^{\prime}(t) I O D(t)-b_{2}{ }^{\prime}(t)$ Monsoon $(t)=S L A^{\prime}$ $-b_{1}{ }^{\prime}(t) I O D(t)-b_{2}{ }^{\prime}(t) M o n s o o n(t)$, and the IOSST index with the decadal ENSO effect removed may, to some degree, represent external forcing. The time series of the decadal variations of these climate indices are shown in Figure 1.

Note that in Equations (3)-(5), we removed the ENSO signals from both the DMI and the monsoon index, as well as monsoon signal from the DMI, to ensure the independence of the predictors. This procedure implies that ENSO affects the IOD and monsoon, and the monsoon affects the IOD, but not the other way around. The caveat is that the IOD and monsoon are integral components of the tropical biennial oscillation [73,74] and that the IOD can also have an active impact on ENSO [75], even though ENSO does have a significant influence on the IOD, particularly during northern winter [36]. Consequently, part of the IOD impact on SLA has been imprinted in the effect of ENSO and the monsoon in Equations (3) and (4), which may result in the overestimation of decadal ENSO and monsoon influences and the underestimation of the decadal IOD effect.

In Bayesian DLM, the SLA is determined not only by the magnitudes of climate indices, but also by their corresponding time-varying coefficients $b_{i}(t)$, as shown by Equations (1)-(5). Physically, this indicates that not all strong climatic events can produce strong SLA. For instance, the strong 1997-1998 eastern Pacific El Niño is associated with a normal Indian summer monsoon, contrasting the drought year that an El Niño often produces. This is because it is the central Pacific El Niño that is more effective in producing subsidence and, therefore, drought over India, compared to the eastern Pacific El Niño [34]. For sea level, the eastern and central Pacific El Niño events-with both being represented by the Nino3.4 index in Bayesian DLM-may have different impacts on the IO regional SLA even though their Nino3.4 indices are the same, because their differences in convection patterns may drive different wind anomalies over the IO. This changing relationship can be captured by $b_{i}(t)$ 
using Bayes theorem in Equation (2), whereas it cannot be captured by the constant $b_{i}$ of SLM. In SLM, the SLA is only determined by the magnitude of the Nino3.4 index. The Bayesian DLM approach has been recently applied to climate studies to understand the non-stationary effects of ENSO and IOD on the inter-annual variability of the Indian Summer Monsoon [76] and Indonesian rainfall [77], and it has also been used to explore the climate modes' impacts on decadal variability of the Indian and Pacific Walker Cells [33].

a) Year mean, original

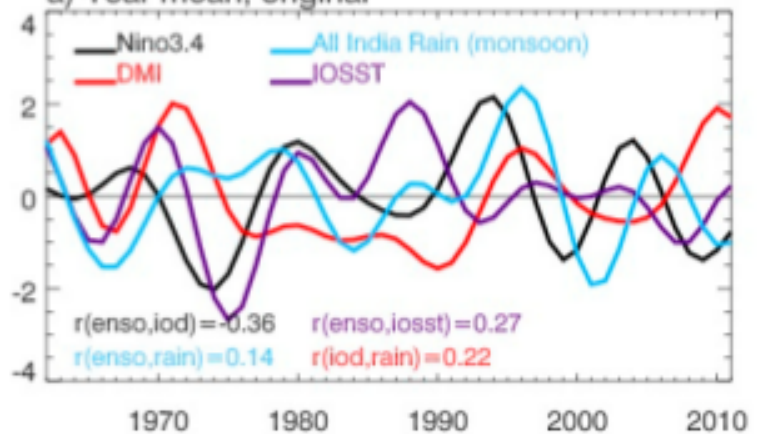

b) Nov-apr, original

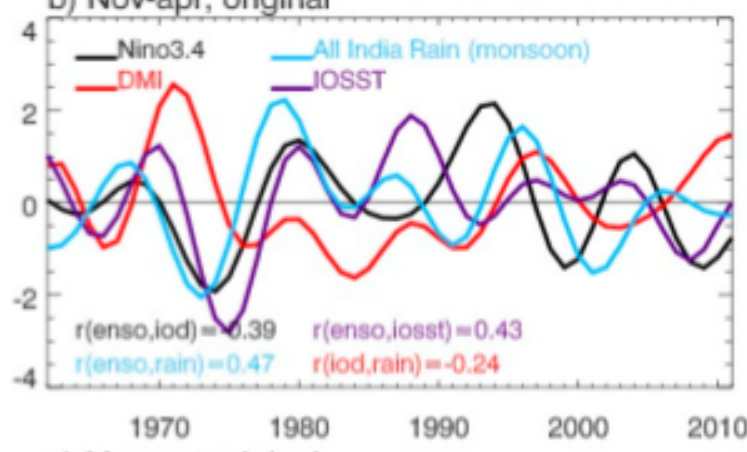

c) May-oct,original

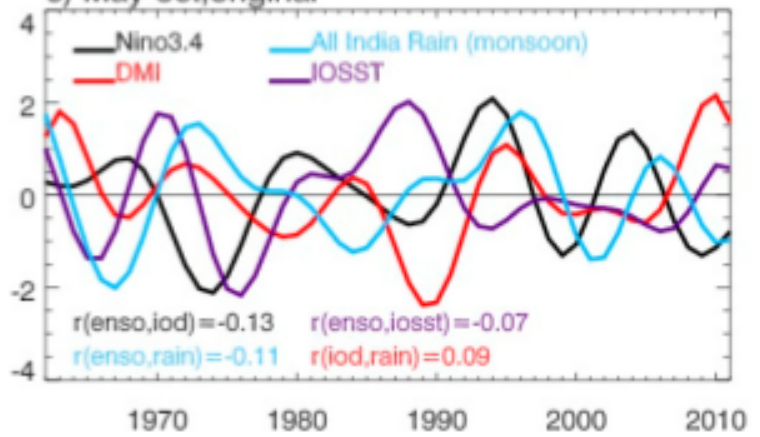

d) Year mean, independent

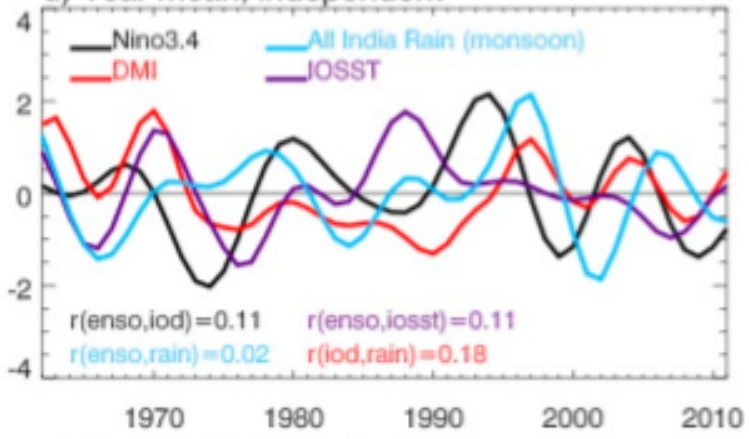

e) Nov-apr, independent

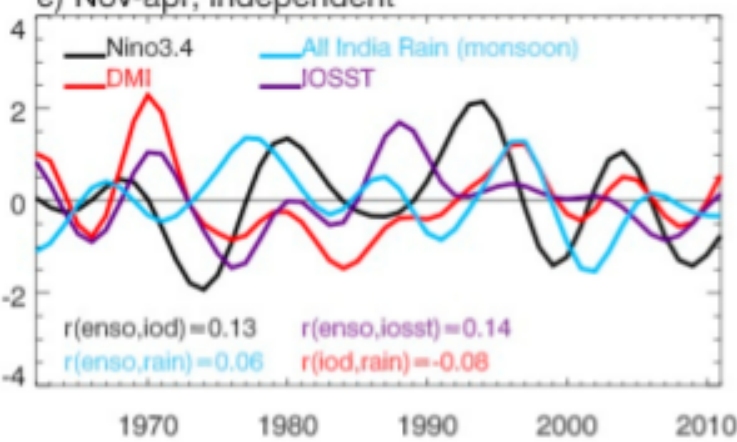

f) May-oct, independent

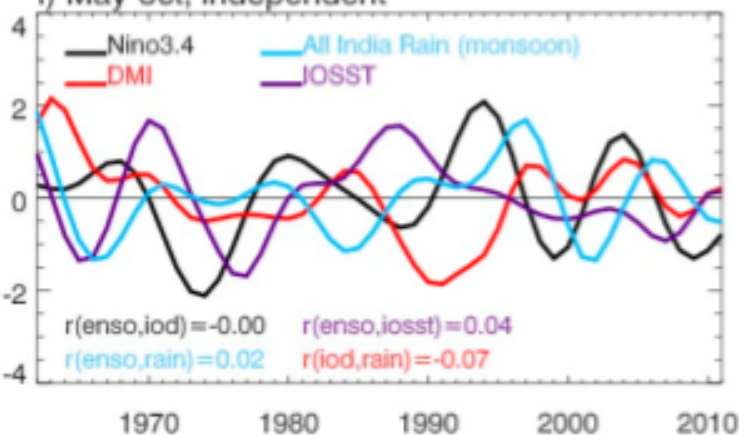

Figure 1. (a) The 8 year low-passed climate indices based on the annual mean Nino3.4 index, Indian Ocean Dipole (IOD) Mode Index (DMI), and the annual total of all India monsoon rainfall (mm) index, and the Indian Ocean SST (IOSST) index; (b) same as (a) but based on winter (November-April) data; (c) same as (a) but based on summer (May-October) data. The 1962-2011 linear trend is removed and each index is normalized by its standard deviation (STD). Panels (d-f) are the same as (a-c), except for removing the El Niño-Southern Oscillation (ENSO) effect on the DMI, monsoon, and IOSST, and removing the monsoon effect on the DMI, using Bayesian dynamical linear model (DLM; see Section 2.4). Consequently, the predictors shown in (d-f) are independent of each other.

\subsection{Choice of Analysis Region}

Our analyses focus on the tropical IO north of $20^{\circ} \mathrm{S}$, because at $20^{\circ} \mathrm{S}$, the oceanic adjustment time, which is the time it takes Rossby waves to cross the basin, is $\sim 5$ year for the first and $\sim 11$ year for the second baroclinic modes, the two gravest modes of oceanic response to surface forcing. Equatorward 
of this latitude, the adjustment times are shorter and decrease with the decrease of latitude [78-80]. This choice ensures that on decadal and longer timescales, the Bayesian DLM can be applied with zero-lag between the climate mode indices and sea level, as shown by Equations (3) and (4). This is because Rossby waves associated with the first two gravest baroclinic modes, together with the barotropic mode which is much faster, have propagated across the tropical IO basin within $~ 10$ years' time. Consequently, variations of surface forcing fields (for example, wind) associated with climate modes are approximately in equilibrium with variations of sea level at timescales of 10 year and longer.

\section{Results}

In this section, we first examine the regional, multi-decadal trend pattern of the sea level over the IO from 1958-2005 when both observational datasets and climate model results are available, and assess the contributions of external forcing versus internal variability to the observed regional trend (Section 3.1). Here, we focus on understanding the "regional distribution of trend" after the global mean SLR, which results largely from anthropogenic warming, being removed. Then, we investigate the decadal variations of the observed sea level (with both global mean and regional trend removed), assess the relative magnitudes of the natural internal variability versus external forcing, and extract the part that is associated with internal climate modes (Section 3.2). Finally, we discuss the importance of winds in driving the regional, decadal sea level patterns (Section 3.3).

\subsection{Multi-Decadal Trends}

The ORAS4 and SODA products show overall consistent spatial patterns of sea level trend from 1958-2005, with the maximum sea-level fall located in the southwestern tropical basin Seychelles Islands region, the weaker sea level fall in the Arabian Sea, and the SLR in the eastern equatorial basin and the Bay of Bengal (Figure 2a,b) where freshwater fluxes due to strong precipitation and the Bay of Bengal river's discharges are large [81]. These patterns resemble those of earlier studies from the standalone ocean model experiments, reanalysis data, and reconstructed sea level for a similar period of time [11-13,82]. Given that global mean SLR has been removed from each dataset, our results suggest that the rates of SLR near the coasts of Sumatra, Java, and the Bay of Bengal from 1958-2005 are considerably larger than the global mean. Note that the vertical land motions detected at some locations near the coasts and the Islands of the IO for the past 20 year [83] may have also affected the sea level trends there.

Qualitative and quantitative differences, however, exist between ORAS4 and SODA. One apparent disparity is in the southeastern basin near the ITF region, where ORAS4 exhibits SLR whereas SODA shows sea level fall. Indeed, the upper $700 \mathrm{~m}$ thermosteric sea level data from both WOA13 and Ishii show falling trends in this area, and also in the Bay of Bengal (Figure 2c,d) where ORAS4 and, to a lesser extent, SODA detect rising trends (Figure 2a,b). Recall that ORAS4 assimilated satellite altimeter data since 1993 but SODA did not (see Section 2.1), and the thermosteric sea level excludes the salinity effect. The disagreements between ORAS4 and SODA (also thermosteric sea level) in the ITF and Bay of Bengal regions suggest that the halosteric sea level associated with an intensified hydrological cycle may have contributed to the multi-decadal SLR in these areas since the 1950s [84-88]. Quantitatively, there are also significant differences. For instance, the falling rate averaged over the Seychelles Islands (boxed region of Figure 2a) is $-1.74 \pm 0.12 \mathrm{~mm}$ year ${ }^{-1}$ in ORAS4 but $-0.73 \pm 0.12 \mathrm{~mm}$ year $^{-1}$ in SODA, which is $\sim 42 \%$ that of ORAS4. Various reasons may contribute to the qualitative and quantitative discrepancies: for example, differences in their OGCMs and surface forcing fields, lack of in situ data that constrain the models in the Seychelles region, and different datasets (for example, altimeter data) assimilated into their models.

Indeed, the trend patterns of ORAS4 from 1993-2010 bear the most resemblance with those of the satellite data (Figure 3a,b), with a pattern correlation of $r=0.84$ ( $>99 \%$ significance). By contrast, the SODA data show a much lower pattern correlation of $r=0.48$ (Figure 3c). The upper $700 \mathrm{~m}$-thermosteric sea level has a pattern correlation of 0.48 for AVISO/WOA13 and 0.73 for AVISO/Ishii (Figure 3d,e). Figure 3 suggests that ORAS4 data most accurately represent the dynamical sea level variability over the IO during 
the satellite era compared to other products; the good agreements between Ishii, AVISO, and ORAS4 data (Figure 3a,b,e) also suggests that the upper-ocean thermosteric sea level is the dominant component for decadal sea level variability, with halosteric sea level being less important even in the eastern basin where the salinity effect is suggested to be important for the multi-decadal trend of SLR (Figure 2).

\section{Indian Ocean regional sea level trend (glmsir removed): 1958-2005}
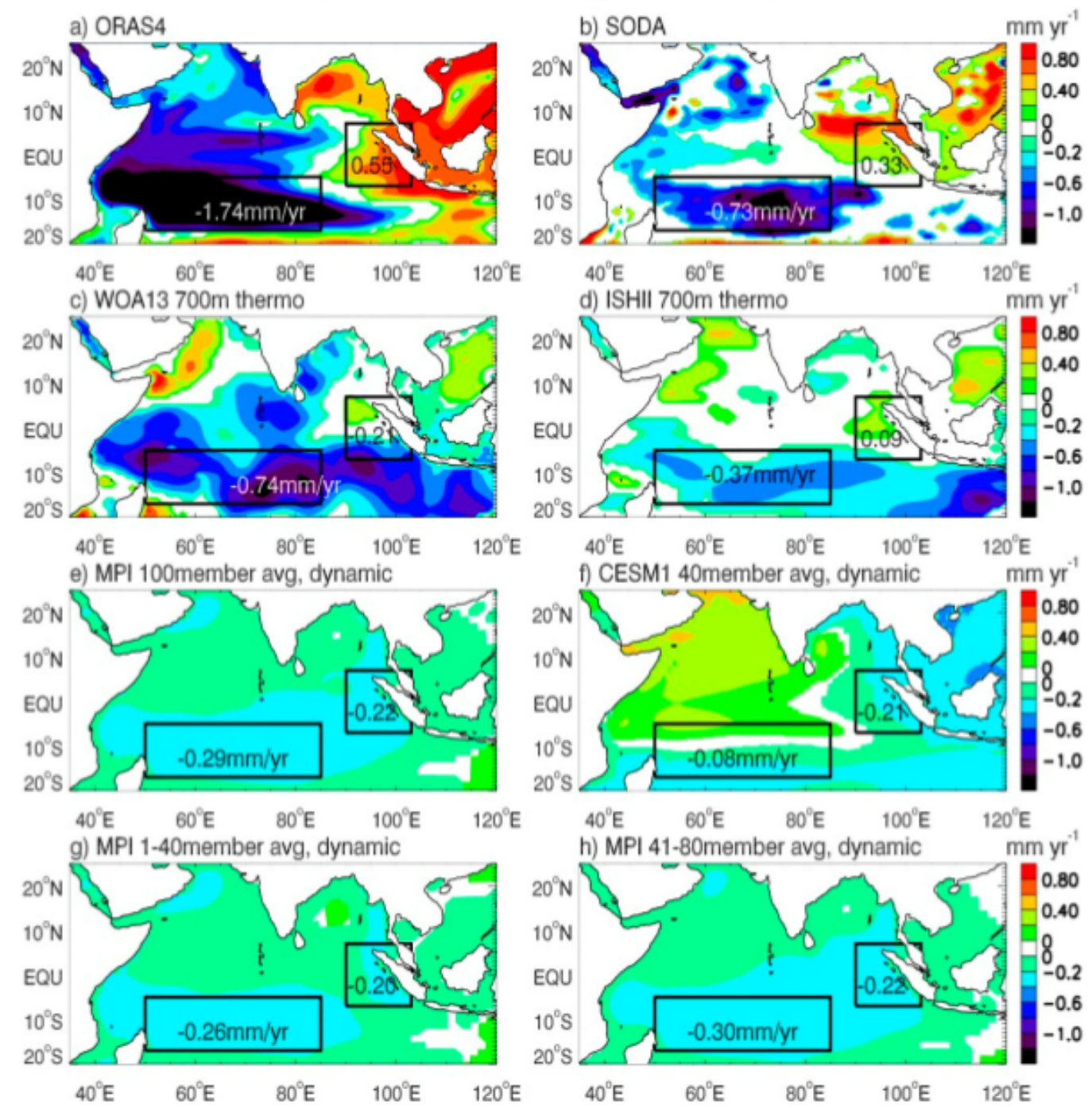

Figure 2. The linear trends of regional sea level over the tropical Indian Ocean from 1958-2005. Monthly data are used, with the 1958-2005 monthly climatology and global mean sea level rise (SLR) time series removed from each dataset before the trend calculation. (a) The ECMWF Ocean Reanalysis System 4 (ORAS4) reanalysis; (b) the Simple Ocean Data Assimilation (SODA) reanalysis; (c) the world ocean atlas 2013 (WOA13) upper $700 \mathrm{~m}$ thermosteric sea level; (d) Ishii upper $700 \mathrm{~m}$ thermosteric sea level; (e) the Max-Planck-Institute of meteorology (MPI) 100-member ensemble mean dynamic sea level; (f) the National Center for Atmospheric Research (NCAR) community earth system model version 1 (CESM1) 40-member ensemble mean dynamic sea level; (g) MPI ensemble mean for members 1-40; (h) MPI ensemble mean for members 41-80. The two boxes show the maximum sea level fall and rise areas in both the ORAS4 and SODA dynamic sea level, with Reg. 1 located in the thermocline ridge of the southwest tropical basin $\left(50^{\circ}\right.$ $\left.\mathrm{E}-85^{\circ} \mathrm{E}, 17^{\circ} \mathrm{S}-5^{\circ} \mathrm{S}\right)$ and Reg. 2, eastern equatorial Indian Ocean $\left(90^{\circ} \mathrm{E}-103^{\circ} \mathrm{E}, 7^{\circ} \mathrm{S}-7^{\circ} \mathrm{N}\right)$. The number in each box shows the trend value of SLA averaged in the box. Trend values exceeding $95 \%$ significance are shown in color contours, and those below $95 \%$ are shown in white. 

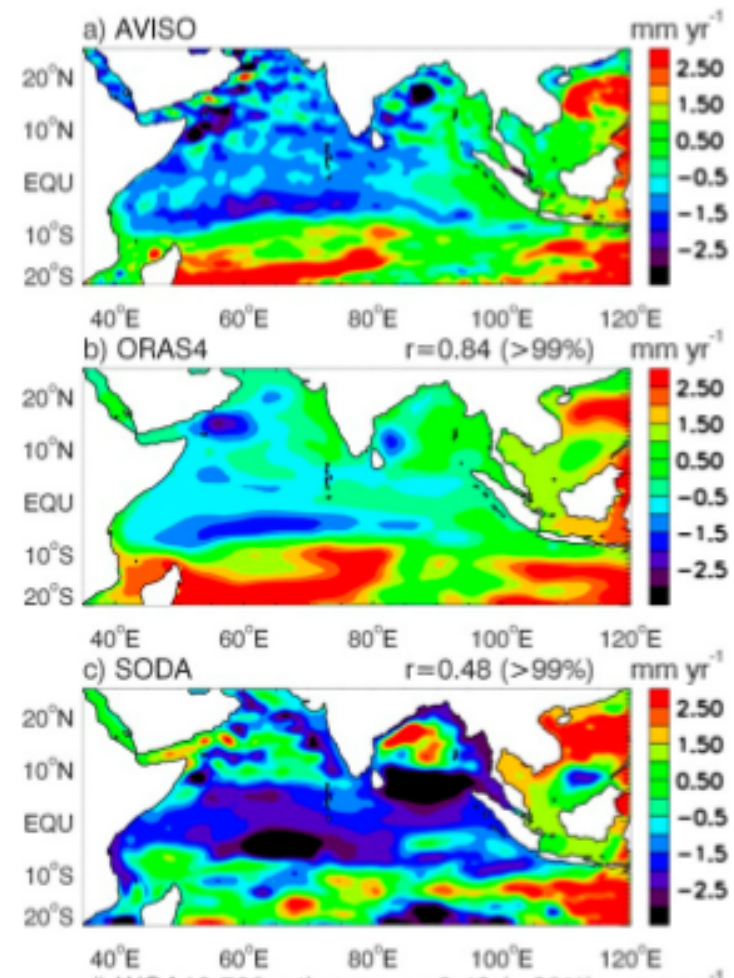

d) WOA13 $700 \mathrm{~m}$ thermo $r=0.48$ (>99\%) $\mathrm{mm} \mathrm{yr}^{4}$

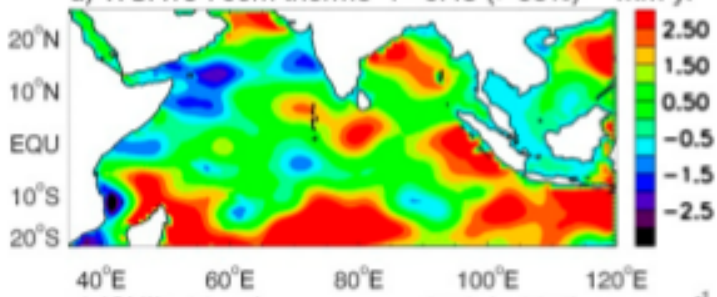

e) ISHII $700 \mathrm{~m}$ thermo $\quad \mathrm{r}=0.73(>99 \%) \quad \mathrm{mm} \mathrm{yr}$

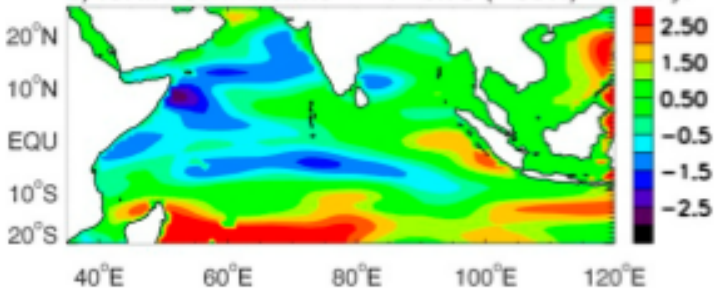

Figure 3. The linear trend map of sea level (mm year ${ }^{-1}$; global mean SLR removed) over the Indian Ocean from 1993-2010, when all datasets are available. (a) The French Archiving, Validation, and Interpolation of Satellite Oceanographic Data (AVISO) satellite altimeter data; (b) ORAS4 reanalysis; (c) SODA reanalysis; (d) WOA13 upper $700 \mathrm{~m}$ thermosteric sea level; (e) Ishii upper $700 \mathrm{~m}$ thermosteric sea level. Spatial pattern correlation coefficient between AVISO and each product is also plotted, with $r=0.84$ for AVISO/ORAS4, 0.48 for AVISO/SODA, 0.48 for AVISO/WOA13, and 0.73 for AVISO/Ishii, with all coefficients exceeding $99 \%$ significance.

Nidheesh et al. [49] examined the decadal SLAs over the Indo-Pacific basin since the 1960s using 10 sea level products from in-situ based, reanalysis, and reconstructed datasets, and their results show significant differences over the IO basin. It is difficult to determine which dataset is the best prior to the satellite era because reanalyses and reconstructions suffer from different issues. For reanalyses, large errors may arise from uncertainties in the model forcing fields, model deficiency, and lack of long-term in situ records to constrain the models. For reconstructions, the spatial patterns of sea level are either fixed to those of the satellite era [89] or assumed to be cyclostationary [82], and their temporal 
variability is constrained by tide gauge observations before the satellite era $[60,82,89]$. There are, however, only a dozen tide gauge stations with record lengths greater than 50 year around the IO rim [90] and no data are available in the ocean interior. Since our research focus is to understand the regional patterns of sea-level variations, we use reanalysis products because they assimilated available observations throughout the basin.

While the sea level trends from ORAS4 and SODA include the effects of both natural internal variability and external forcing, the 100-member ensemble average of MPI model (with global SLR removed) isolates the effect of external forcing on the regional distribution of sea-level variations. Its trend patterns resemble that of ORAS4 in most regions of the IO, such as the evident sea level fall in the southwest basin, a weaker fall in the Arabian Sea, and a rise in the southeast basin near the ITF region (compare Figure 2a,e). An exception is the eastern equatorial basin and the Bay of Bengal, where the MPI model produces a sea level fall instead of the SLR shown in ORAS4 and SODA (Figure 2; the right column of Table 1). This difference may reflect the true effect of external forcing, but it may also arise from the common climate model biases associated with convection and winds, which resulted in an underestimated SLR there in the eastern IO [91-93]. Based on the 100-member ensemble mean of the MPI model, external forcing contributes $-0.29 \pm 0.04 \mathrm{~mm}_{\text {year }}{ }^{-1}$ to the falling trend of the thermocline ridge (Figure 2e; Table 1), which is $\sim 17 \pm 2.3 \%$ of that from ORAS4 and $\sim 40 \pm 5.5 \%$ from SODA.

Table 1. The linear trends ( $\mathrm{mm}_{\text {year }}{ }^{-1}$ ) of regional sea level with global sea level rise (SLR) removed (that is, departure from the global mean) averaged in the Seychelles area and in the eastern equatorial basin (boxed regions of Figure 2) for the period of 1958-2005 from observations and climate model simulations. Observations are based on monthly ECMWF Ocean Reanalysis System 4 (ORAS4) and Simple Ocean Data Assimilation (SODA) reanalysis products, with all trend values exceeding 95\% significance and errors being the slope uncertainties of linear fitting. The model simulations are from the Max-Planck-Institute of meteorology (MPI) 100-member ensemble, National Center for Atmospheric Research (NCAR) community earth system model version 1 (CESM1) 40-member ensemble, and their total of 140-member ensemble; their trend values are obtained from the 100-member ensemble averages of external forcing effect, with each of the 100 members being an ensemble mean of randomly chosen $\mathrm{N}$ members using the Monte Carlo method; uncertainties indicate 1.65 standard deviations of the external forcing spread, as discussed in detail in the text.

\begin{tabular}{|c|c|c|}
\hline & $\begin{array}{l}\text { West: Tropical South IO (Seychelles) } \\
\left(50^{\circ} \mathrm{E}-85^{\circ} \mathrm{E}, 17^{\circ} \mathrm{S}-5^{\circ} \mathrm{S}\right)\end{array}$ & $\begin{array}{c}\text { East: EQ Indian Ocean } \\
\left(90 \text { boldsymbol }{ }^{\circ} \text { E-103 } 103^{\circ} \text { E, } 7^{\circ} \mathrm{S}-7^{\circ} \mathrm{N}\right)\end{array}$ \\
\hline Obs-ORAS4 & $-1.74 \pm 0.12$ & $0.55 \pm 0.13$ \\
\hline Obs-SODA & $-0.73 \pm 0.12$ & $0.33 \pm 0.12$ \\
\hline Obs-mean & $-1.23 \pm 0.12$ & $0.44 \pm 0.12$ \\
\hline MPI 100 & $-0.29 \pm 0.04$ & $-0.22 \pm 0.03$ \\
\hline CESM1 40 & $-0.08 \pm 0.07$ & $-0.21 \pm 0.06$ \\
\hline Model-mean & $-0.23 \pm 0.03$ & $-0.22 \pm 0.03$ \\
\hline
\end{tabular}

Compared to the MPI 100-member ensemble average, the 40-member ensemble mean of CESM1 shows some similarities in sea level patterns; but the falling trend extends farther to the south, yielding a $\sim 0$ trend averaged in the southwest basin boxed region over Seychelles. If we move the box southward by $10^{\circ}$, the averaged value is $-0.21 \mathrm{~mm}$ year ${ }^{-1}$, which is close to the $-0.29 \mathrm{~mm}$ year ${ }^{-1}$ from the MPI model (Figure 2e,f). Randomly chosen 40-member ensemble means of MPI show similar sea level trend patterns to the 100-member average, even though there are still some quantitative differences in some areas (compare Figure 2e,g,h). Over the north IO, the two models show overall similar patterns but with significant quantitative differences. While both model simulations yielded a sea level fall in the eastern equatorial basin, CESM1 produces a SLR but MPI generates a weak sea level fall in the Arabian Sea and the western Bay of Bengal. CESM1 shows falling sea level over the entire eastern IO, including the ITF region where ORAS4 and MPI model show rising sea level. This pattern resembles the bias of an overly strong east-west dipole pattern in the predecessor of the CESM1 model [91-93]. 
The above results indicate that the 40-member ensemble average can reasonably damp the natural internal variability in the multi-decadal (1958-2005) regional sea level trend, and the differences between the MPI 100-member and CESM1 40-member ensemble averages arise mainly from the differences between the two models. Since the observed $\mathrm{IO}$ warming in the past few decades can induce surface winds that likely drive a similar sea level pattern to Figure 2e in most regions of the tropical IO [11], and the warming has been attributed primarily to anthropogenic forcing [16,17], there is reason to believe that the MPI model may have produced more reasonable externally-forced sea level trend patterns than CESM1. Indeed, apparent differences between MPI and CESM sea level trends exist over the entire Indo-Pacific basin, with opposite signs occurring in some regions (for example, the western tropical Pacific; figure not shown). Their large disparity suggests that the two models have very different responses to the same external forcing, yielding different or even opposite sea level trends in some regions.

Using the 140-member ensemble mean of the two models (100 MPI and 40 CESM1) to represent external forcing $\left(-0.23 \pm 0.03 \mathrm{~mm}\right.$ year $\left.{ }^{-1}\right)$, and the average of ORAS4 and SODA to represent observation $\left(-1.23 \pm 0.12 \mathrm{~mm}\right.$ year $\left.{ }^{-1}\right)$, external forcing contributes $19 \pm 2.4 \%$ of the observed falling trend over the Seychelles area (Model-mean versus Obs-mean in Table 1; see Supplementary Figure S1 for bar graph). Using the MPI 100-member average to represent external forcing, the ratio of the forced/observed trend value becomes $24 \pm 3.3 \%$ over the Seychelles area. Since the climate models produce a falling trend in the eastern equatorial $\mathrm{IO}$ where observations detect a rising trend, the external forcing contributes less to the observed east-west contrasting pattern (Figure 2; Table 1) than to the Seychelles falling trend. Be aware that the mean of the two reanalysis products may not adequately represent the ensemble mean of the multiple reanalysis datasets [94] and the true observational values, giving rise to a larger uncertainty in the estimated ratio for external forcing.

Note that here, we use the Monte Carlo method to calculate the uncertainty of external forcing because the conventional approach of directly calculating the ensemble member spread (represented by 1.65 standard deviation (STD)) used in Slangen et al. and Meyssignac et al. [95,96] does not apply to our case. This is because after global SLR is removed, the ensemble average-which assesses the effect of external forcing-has a weak magnitude, and this weak signal is overwhelmed by the large-amplitude internal variability in each ensemble member. The trend spread (1.65STD) is 2.5 times that of the trend signal of the ensemble mean for 1958-2005, and the spread is way larger than the signal for decadal SLA (Supplementary Figure S2). Physically, the huge spread demonstrates that natural internal variability dominates over external forcing and it cannot be used to represent the "uncertainty range" of external forcing here, even though it worked for the situation when global SLR was retained $[95,96]$. To properly assess the uncertainty of the external forcing effect, we first randomly choose $\mathrm{N}$ members from one model ensemble, and then obtain the $\mathrm{N}$-member ensemble average to represent "external forcing effect". Using this procedure, we obtain a set of 100 members for external forcing, with each being a N-member ensemble mean. Then we calculate the 100-member average and spread (1.65STD) to measure the effect of external forcing and uncertainty. Size $\mathrm{N}$ is chosen to ensure that the N-member ensemble mean can reasonably damp the internal variability. Based on our test and analysis (Supplementary Figure S3), choosing $\mathrm{N}$ as $\sim 70 \%$ of the total members will reduce the uncertainty of the externally forced decadal SLA to below the signal values in both the western and eastern basins. Consequently, we use $N=98,70$, and 28 for the total model (MPI + CESM1), MPI, and CESM1, respectively. For the 1958-2005 trend, using $N=40$ yields reasonable results (not shown). For consistency, however, we use the same $\mathrm{N}$ values for the multi-decadal trend (Table 1) and decadal SLA (discussed below) to assess the effects of external forcing and their uncertainties.

\subsection{Decadal Variations}

\subsubsection{Natural Internal Variability Versus External Forcing}

To understand in which areas the observed decadal (8 year lowpass filtered) SLAs obtain their largest amplitudes, we calculate their STD maps using the annual mean SLAs from the ORAS4 and SODA 
data (Figure $4 \mathrm{a}-\mathrm{c}$ ). Albeit with quantitative differences between the two reanalysis products, decadal SLAs reach their maximum magnitudes over the Seychelles region (Reg. 1 of Figure $4 a-c)$ where the multi-decadal trend is also the strongest (see Figure 2), near the ITF area north of Australia (Reg. 2), and to a lesser degree, along the perimeter of the Bay of Bengal for both datasets. The maximum decadal SLA in the Seychelles region is consistent with the result of Li and Han (2015) [28]. The STD of SLA averaged over Reg. 1 is $15.5 \mathrm{~mm}$ for ORAS4 and $9.8 \mathrm{~mm}$ for SODA, and the correlation between the two is $r=0.46$ (below 90\% significance; Figure 4g). For Reg. 2, the STD is $14.9 \mathrm{~mm}$ for ORAS4 and $17.1 \mathrm{~mm}$ for SODA, and their correlation coefficient is $r=0.72$ (>95\% significance). The less agreement over Reg. 1 further supports our earlier argument regarding the lack of observations in this area for constraining the models, yielding larger uncertainties of the detected decadal SLA in the Seychelles region.

STD map for decadal SLA (mm): 1962-2001
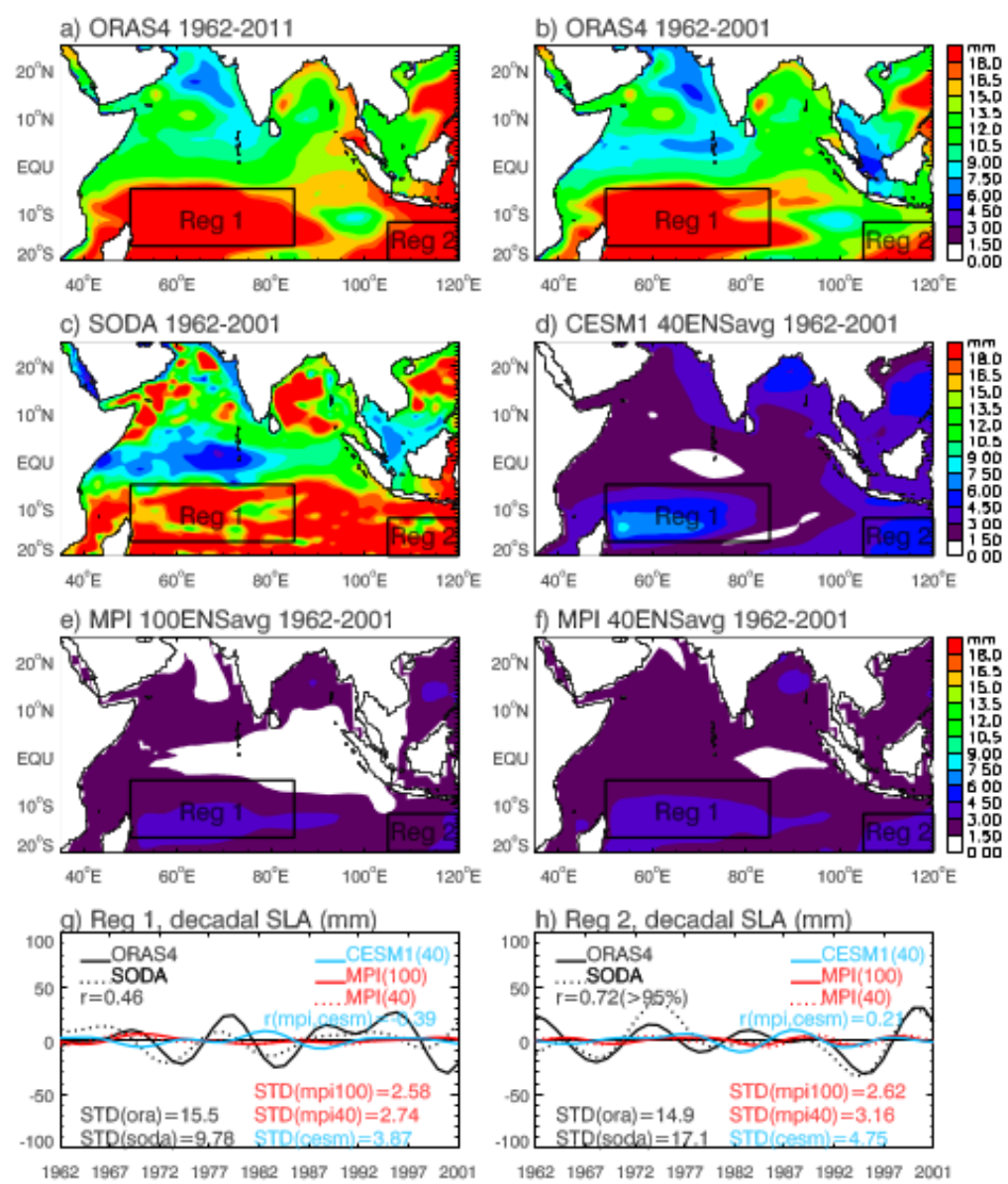

Figure 4. (a) The standard deviation (STD) map of decadal SLA (with global mean SLR and regional trend removed) from ORAS4 reanalysis over the tropical Indian Ocean for the 1962-2011 period. First, the global SLR was removed from the monthly sea level data for 1958-2015; then monthly climatology and the linear trend at each grid point were removed; finally, a Lanczos 8 year lowpass filter was applied; the first and last four years of data (1958-1961 and 2012-2015) are excluded to remove the endpoint effect of the filter; the two boxes show the maximum STD regions, with Reg. 1 representing the thermocline ridge $\left(50^{\circ} \mathrm{E}-85^{\circ} \mathrm{E}, 17^{\circ} \mathrm{S}-5^{\circ} \mathrm{S}\right)$ shown in Figures 2 and 4 , and Reg. 2, the near ITF region $\left(105^{\circ} \mathrm{E}-120^{\circ} \mathrm{E}, 2^{\circ} \mathrm{S}-12^{\circ} \mathrm{S}\right)$; (b) same as (a) but for the ORAS4 for the 1962-2001 period; (c) same as (b) but for the SODA reanalysis data from 1962-2001; (d) same as (b) but for the CESM1 40-member ensemble mean from 1962-2001; (e) same as (d) but for the MPI 100-member ensemble mean from 1962-2001; (f) same as (e) but for the MPI 40-member ensemble mean; (g) the time series of decadal SLA averaged over Reg. 1; (h) same as (g) but for the decadal SLA averaged over Reg. 2. Units: mm. 
External forcing also induces its largest decadal SLA over the Seychelles Islands, near the ITF and in the Bay of Bengal (Figure $4 \mathrm{~d}-\mathrm{f}$ ), the regions where strong variability occurs in the reanalysis data (Figure $4 \mathrm{a}-\mathrm{c}$ ). The largest magnitude over Seychelles suggests that the shallow, mean thermocline there is prone to the influence of external forcing and internal climate variability. Comparing the MPI 100and 40-member ensemble averages, we see apparently weaker magnitudes in the 100-member mean (compare their STD values in Figure 4e-h). The STD of the 100-member averaged SLA is $2.58 \mathrm{~mm}$ in Reg. 1 , which is $\sim 17 \%$ of the STD of ORAS4 and $\sim 26 \%$ of SODA. For Reg. 2 , the 100-member mean SLA STD is $2.62 \mathrm{~mm}$, which is $\sim 18 \%$ of the STD of ORAS4 and $\sim 15 \%$ of SODA. Compared to the MPI model, CESM1 produces larger SLAs (compare Figure $4 \mathrm{~d}-\mathrm{h}$; also see Figure $5 \mathrm{~b}, \mathrm{c}, \mathrm{e}, \mathrm{f}$ ). The correlation between the 40-member ensemble averages from the MPI and CESM1 is -0.39 for Reg. 1 and 0.2 for Reg. 2, and neither correlation coefficient is statistically significant at $90 \%$. The large differences between the two models suggest that decadal SLAs induced by the external forcing of the climate system are highly sensitive to the models, and it is unknown which model produces the correct response in nature. For this reason, we cannot simply subtract the effect of external forcing from observations to obtain the effect of internal variability.
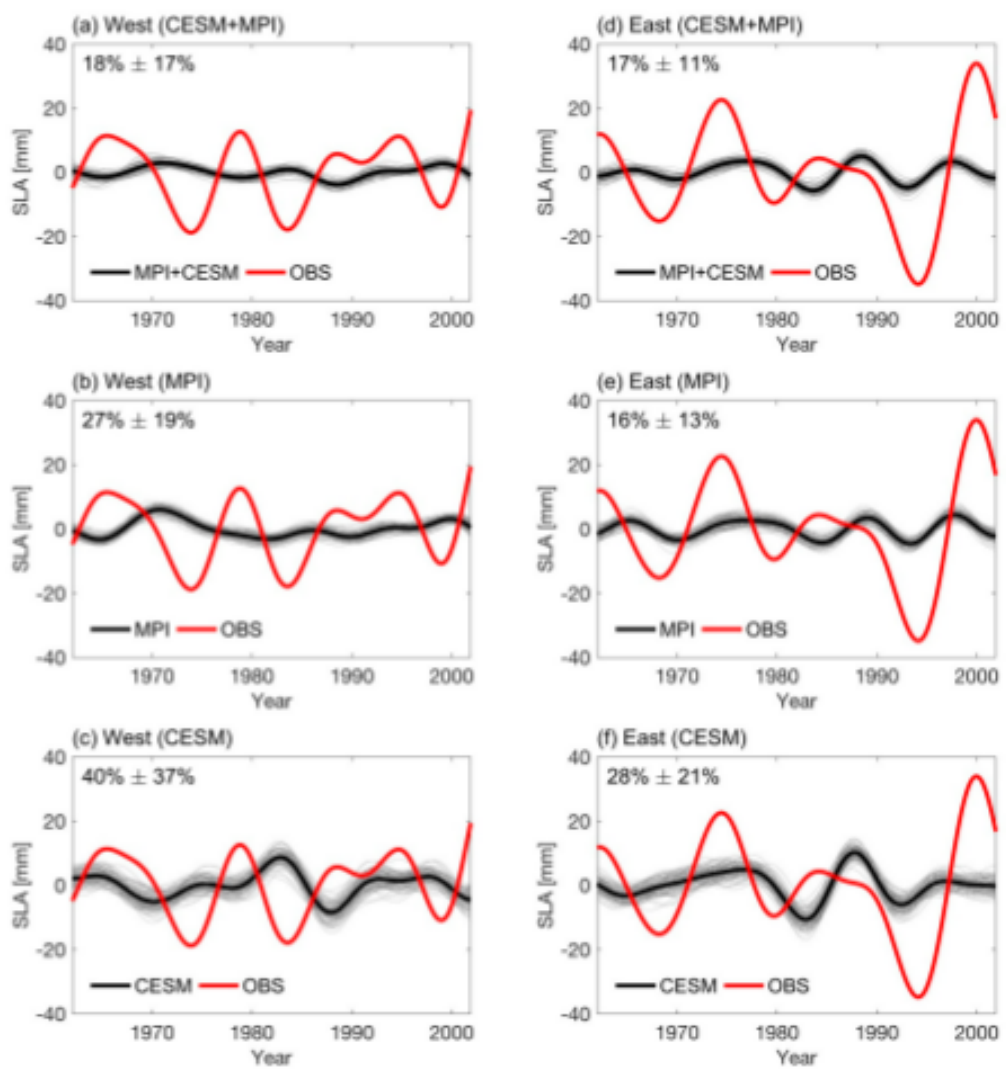

Figure 5. The time series of the 8 year lowpass filtered decadal SLA ( $\mathrm{mm}$ ) averaged over the Seychelles Island area in the west (Reg. 1 of Figure 4) and near the ITF area in the east (Reg. 2 of Figure 4) from 1962-2001. (a) The time series of the 100 members that represent external forcing, with each member being the ensemble average of the randomly chosen $\mathrm{N}$ members from the total MPI and CESM (140 members) averaged in Reg. 1 (thin curves), the effect of the external forcing represented by the 100-member ensemble mean (thick black curve), and the observation represented by the average of ORAS4 and SODA (red curve); the $18 \pm 17 \%$ are the STD ratios between the external-forced and observed SLA and its uncertainty (1.65STD of spread, shown by the gray shading); $(\mathbf{b}, \mathbf{c})$ are the same as (a) but for the MPI 100 members and the CESM 40 members, respectively; (d-f) are the same as (a-c) except that they are averaged in Reg. 2. See the last paragraph of Section 3.1 for a detailed discussion on the Monte Carlo method to obtain the 100 members of external forcing and the choice of $N$. 
Using the 1962-2001 STD of the ORAS4 and SODA average to represent observation (STDo), and the 1962-2001 STD of the 100-member mean of the external forcing ensemble (see detailed descriptions above) from the total MPI + CESM1 to represent external forcing (STDem), we obtain their ratio, STDem/STDo, as $18 \pm 17 \%$ in the Seychelles region and $17 \pm 11 \%$ near the ITF area (Figure $5 \mathrm{a}$,d). The uncertainty is the ratio between 1.65STD of the 100-member spread (STDes) and the observation, 1.65STDes/STDo, which is $17 \%$ in the Seychelles region and $11 \%$ near the ITF. These results clearly demonstrate that natural internal variability is the predominant cause for the observed decadal SLA in the two regions where both observed and externally forced signals reach their maxima (Figure 4).

\subsubsection{Effects of Climate Modes}

Given that ORAS4 data more accurately represent the decadal sea level trends than SODA during the satellite era of 1993-2010 (Figure 3) and that the dataset has a longer record, hereafter, we use ORAS4 data to assess the decadal SLAs associated with climate modes.

(a) Contribution in regions of large SLA. Evidently, climate modes plus IOSST, which is independent of decadal ENSO and partly represents external forcing (Section 2.4), can explain most of the observed variances of the decadal SLAs based on annual mean data, and climate modes (ENSO + IOD + monsoon) are the main contributor in all key regions where the observed SLA STDs are large (Figure 6a-c), with IOSST (Figure 6h) having identifiable contributions over Seychelles (Reg. 1), the Sumatra coasts (Reg. 3), and the Bay of Bengal coasts (Reg. 4). Each individual mode is associated with distinct SLA patterns (Figure 6e-g), with ENSO contributing the most in the south IO over Seychelles and near the ITF (Reg. 2), IOD over Seychelles, and monsoon over Seychelles, the Sumatra coasts, and Bay of Bengal coasts. It appears that monsoon variability dominates decadal SLA along the coasts of Sumatra and the Bay, with ENSO and IOD having weak contributions there, even though the east antinode of the IOD covers a large part of Reg. 3. As we shall see below, this contradiction arises partly from the strong seasonality of climate modes and, thus, the seasonality of their impacts.

To reveal the seasonality of the SLA associated with climate modes, we calculated the decadal SLA based on the boreal winter (November-April) and summer (May-October) mean values. These months are chosen for the following reasons: (1) ENSO reaches its peak amplitude during boreal winter, and Indian summer monsoon rainfall obtains its maximum during boreal summer, that is, May-October; (2) For the IOD, about one third of events are associated with ENSO and two thirds are independent of ENSO; the independent IOD events usually develop in June and quickly weaken after October [36]; and (3) November-April and May-October have been characterized as the wet and dry seasons of Indonesia that resides in the region of Indo-Pacific warm pool convection [77], and were used to document the seasonality of the relationships between decadal variability of the Indo-Pacific Walker Cells and climate modes [33].

During November-April, climate modes can explain most of the SLAs in all key regions, but IOSST also has non-negligible contributions (Figure 7a-c,h), similar to the annual mean (Figure 6). The residual, the portion unexplained by climate modes and IOSST, is weak in all other areas but Reg. 1, where both the observed SLA and data uncertainty are the largest, as discussed earlier. While the decadal ENSO has its largest influence in the south IO as the annual mean (Regs. 1-2, Figure 7e), it also exerts a strong influence on SLA along the Sumatra and Bay of Bengal coasts (Regs. 3-4). The effect of the monsoon is comparable to ENSO in all regions except for the ITF area (Figure 7g). The IOD has a significant contribution only over Seychelles. The weak influence of the decadal IOD near the Sumatra coast is likely because we removed the ENSO signals from the IOD index in Equation (4). Consequently, the impact of the ENSO-associated IOD on SLA is imprinted in the effect of ENSO; this procedure may overestimate the impact of ENSO but underestimate the effect of IOD, a caveat that was pointed out in Section 2.4. 
STD map for 8yrlp SLA (mm): 1962-2011 yrmean

a) ORAS4

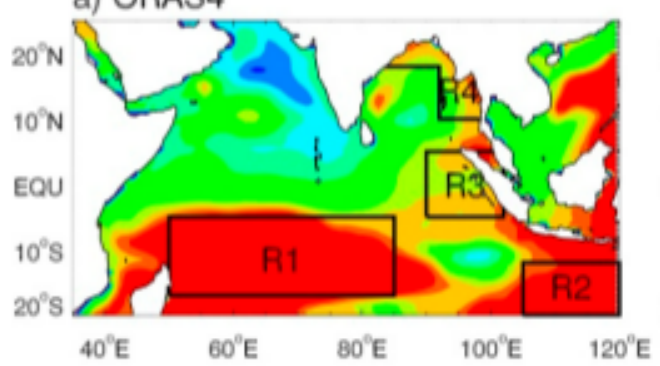

b) All modes+IOSST

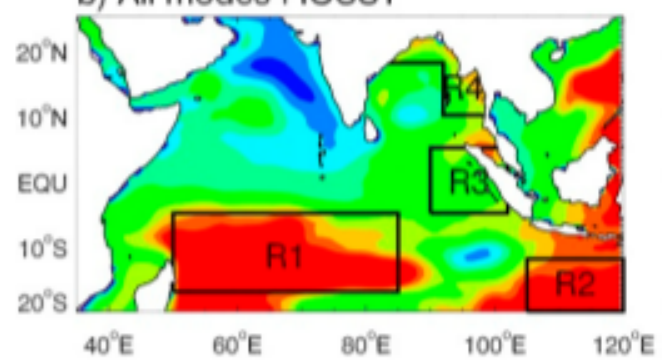

c) All modes

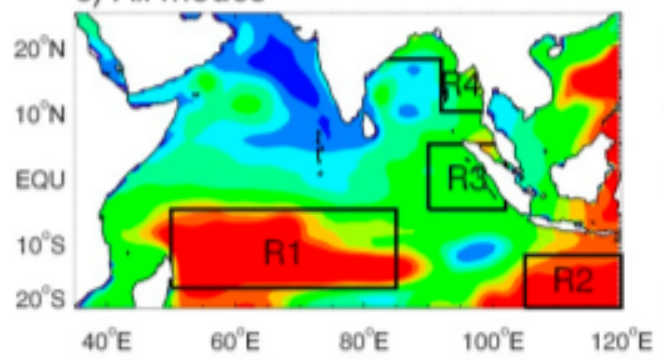

d) Residual: (a) - (b)

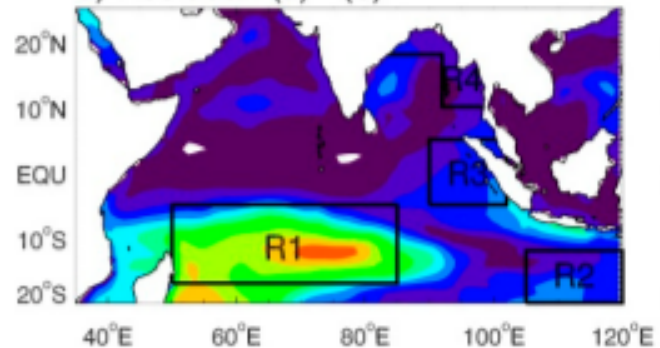

e) ENSO
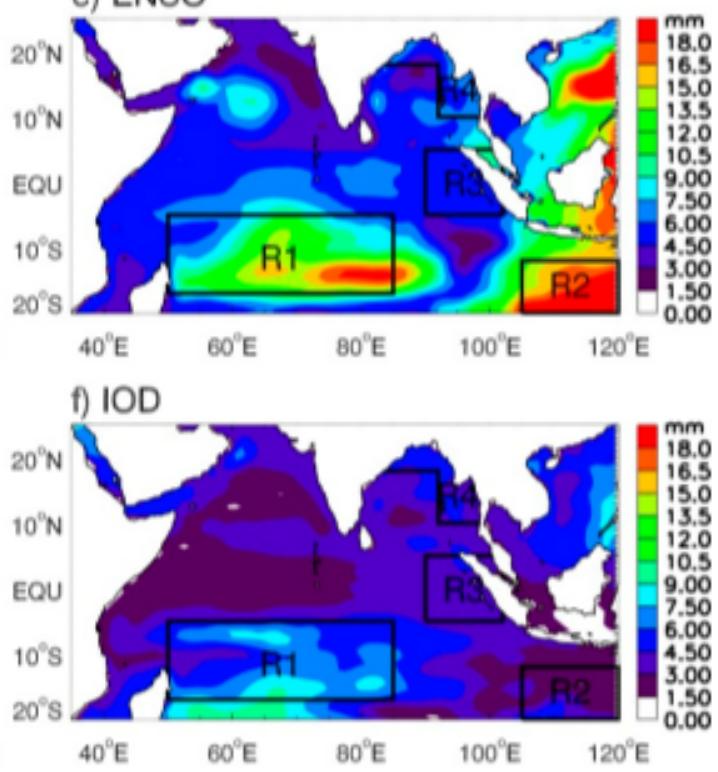

g) Indian monsoon

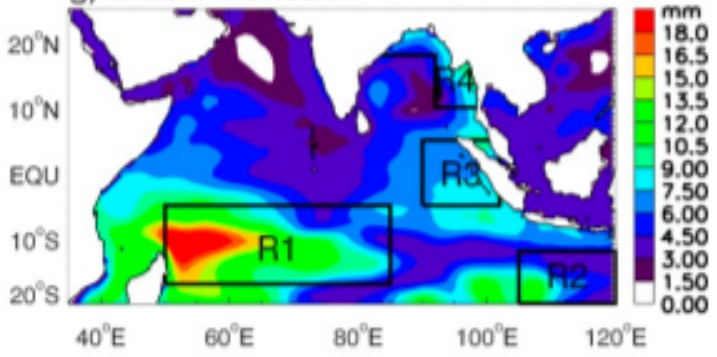

h) IOSST

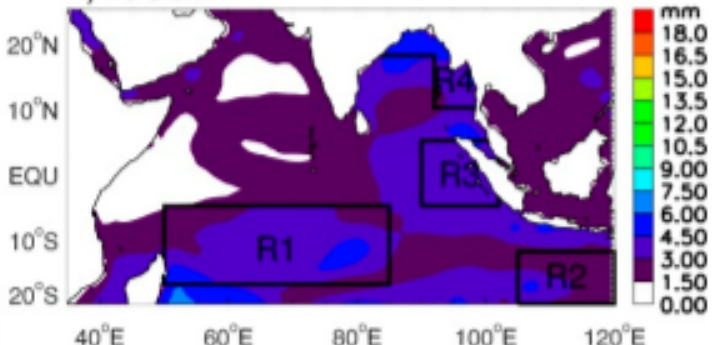

Figure 6. (a) The standard deviation map of ORAS4 8 year low-passed SLA for the 1962-2011 period based on the yearly mean (all 12 months) sea level data; it is the same as Figure 4a except for adding boxed region $\mathrm{R} 3$ in the eastern equatorial basin $\left(90^{\circ} \mathrm{E}-102^{\circ} \mathrm{E}, 5^{\circ} \mathrm{S}-5^{\circ} \mathrm{N}\right)$ and boxed region $\mathrm{R} 4$ in the Bay of Bengal coast. R4 consists of an area east of $92^{\circ} \mathrm{E}$ but north of $10^{\circ} \mathrm{N}$ and an area west of $92^{\circ} \mathrm{E}$ but north of $18^{\circ} \mathrm{N}$; (b) same as (a) but for SLA associated with all climate modes (ENSO + IOD + monsoon) plus the effect of IOSST, which to some extent represents external forcing; (c) same as (b) but only for climate modes (ENSO + IOD + monsoon), and it equals the IOSST effect subtracted from panel (b); (d) same as (b) but for the residual, difference for $(\mathbf{a}, \mathbf{b})$, measuring the effects that cannot be explained by the climate modes and IOSST; (e-h) are the same as (b) but for the individual effect of decadal ENSO, IOD, monsoon, and IOSST. Units: $\mathrm{mm}$. The boxed regions have large variances and are used to calculate the time series later. 

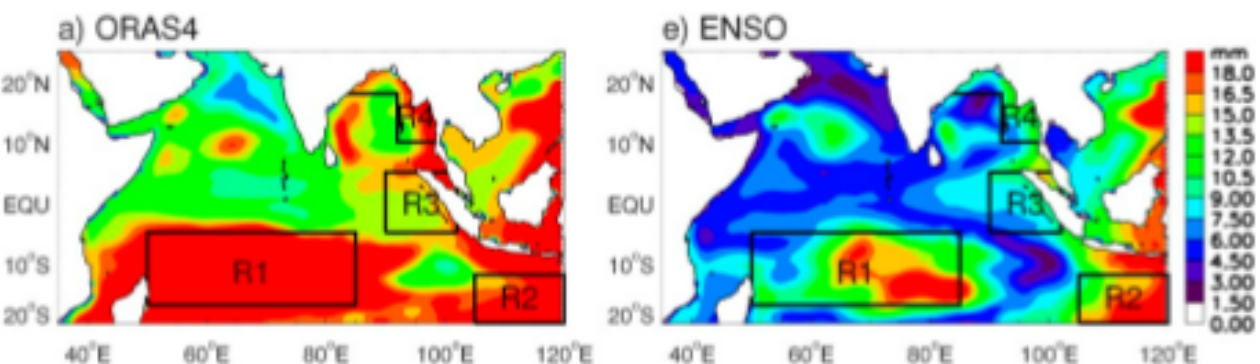

b) All modes+IOSST
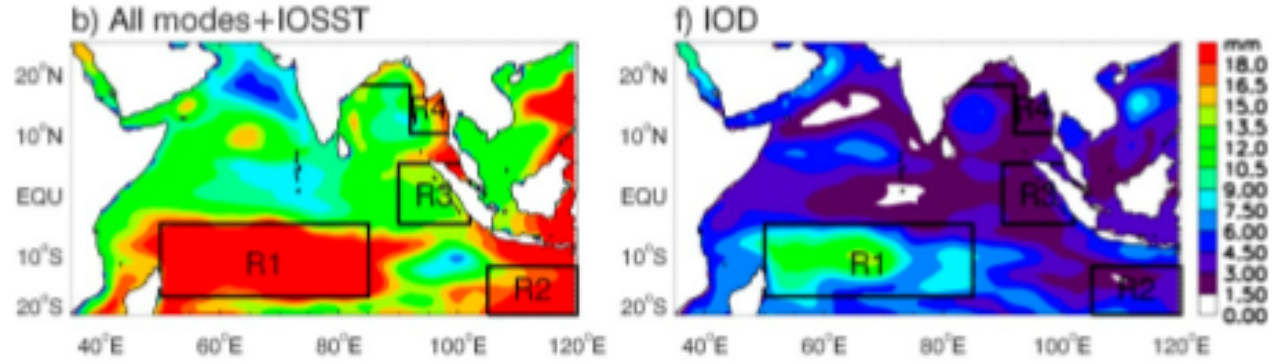

\section{c) All modes}
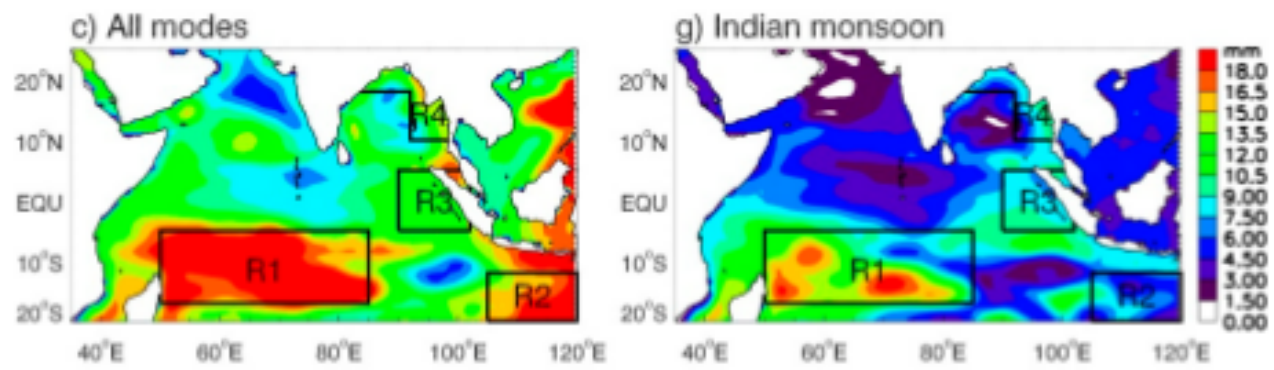

d) Residual: (a) - (b)
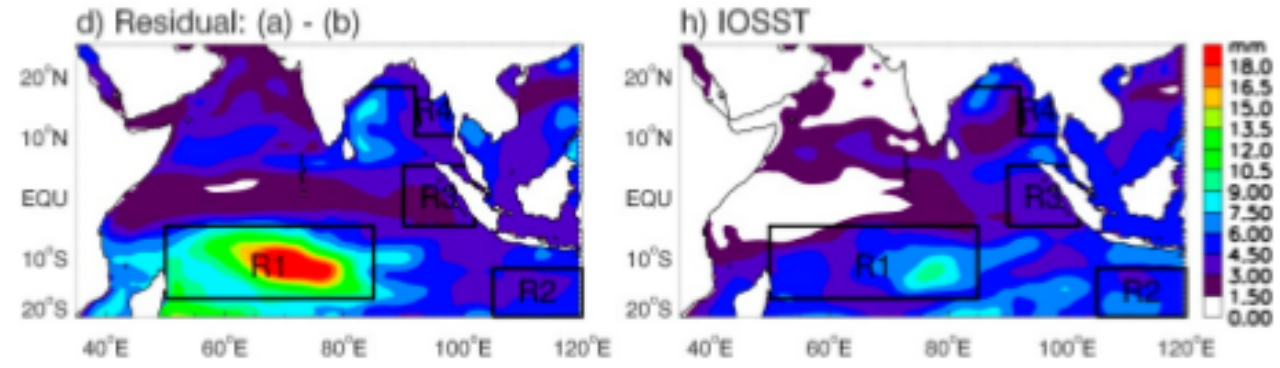

Figure 7. (a) The standard deviation map of the ORAS4 8 year low-passed SLA for the 1962-2011 period of the northern hemisphere winter season, based on the November-April averaged data of each year; (b) same as (a) but for SLA associated with all climate modes (ENSO + IOD + monsoon) plus the effect of IOSST which, to some extent, represents external forcing; (c) same as (b) but only for climate modes (ENSO + IOD + monsoon) and it equals the IOSST effect subtracted from panel (b); (d) same as (b) but for the residual, difference for $(\mathbf{a}, \mathbf{b})$, measuring the effects that cannot be explained by the climate modes and IOSST; (e-h) are the same as $(\mathbf{b})$ but for the individual effect of decadal ENSO, IOD, monsoon, and IOSST. Units: $\mathrm{mm}$. The figure is the same as Figure 6 except for northern winter season.

Similar to winter, climate modes and IOSST (ENSO + IOD + monsoon + IOSST) explain most of the observed SLA variances in all regions during summer. Different from winter, climate modes contribute less to the observed variances near the Sumatra, Java, and Bay of Bengal coasts, and the errors are apparently larger in these regions compared to winter (compare Figures $7 a-d$ and $8 a-d$ ). In addition, during May-October, the strong impacts of ENSO are confined to the south IO (Regs. 1 and 2), with little influence on the SLAs around the Bay of Bengal rim and west coasts of Sumatra (Figure 8e). The IOD, on the other hand, has the strongest influence on SLAs near the Sumatra and 
Bay of Bengal coasts, compared to the impacts of ENSO and the monsoon (Figure 8e-g). The large IOD impact on the coastal areas of the eastern IO results from the fact that most of the IOD events that are independent of ENSO develop in early summer and quickly weaken after October [36]. The IOD, together with monsoon and IOSST, is responsible for a large fraction of the observed SLAs near the east IO coasts (Figure $8 \mathrm{f}-\mathrm{h}$ ).

\section{STD map for 8yrip SLA (mm): 1962-2011 mayoct}
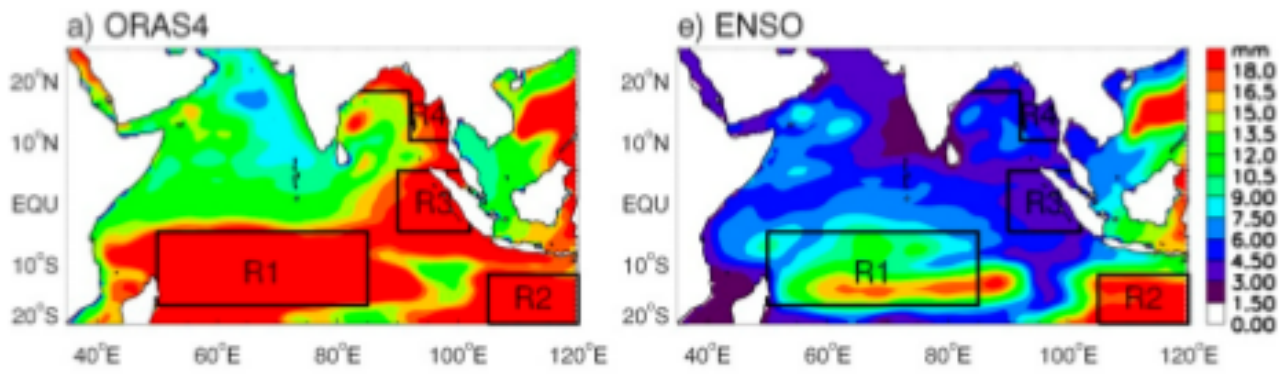

b) All modes+IOSST
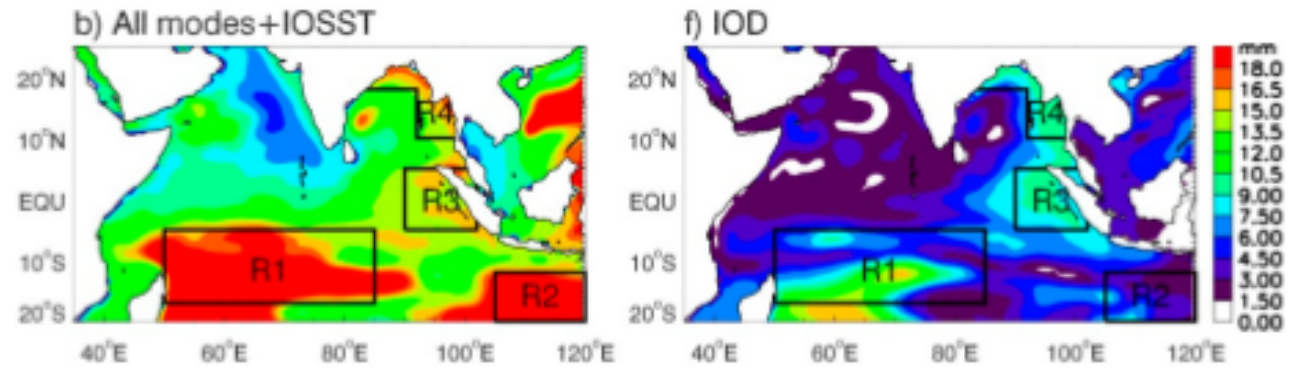

c) All modes
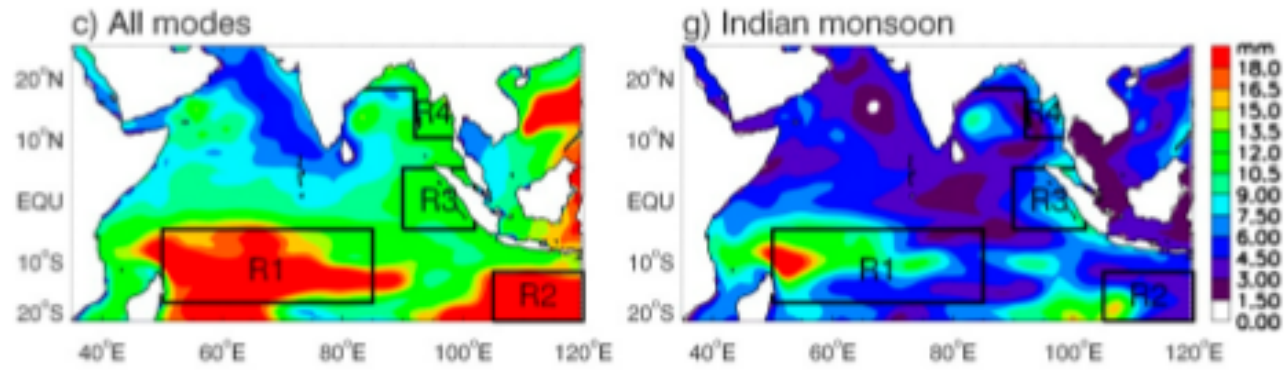

d) Residual: (a) - (b)
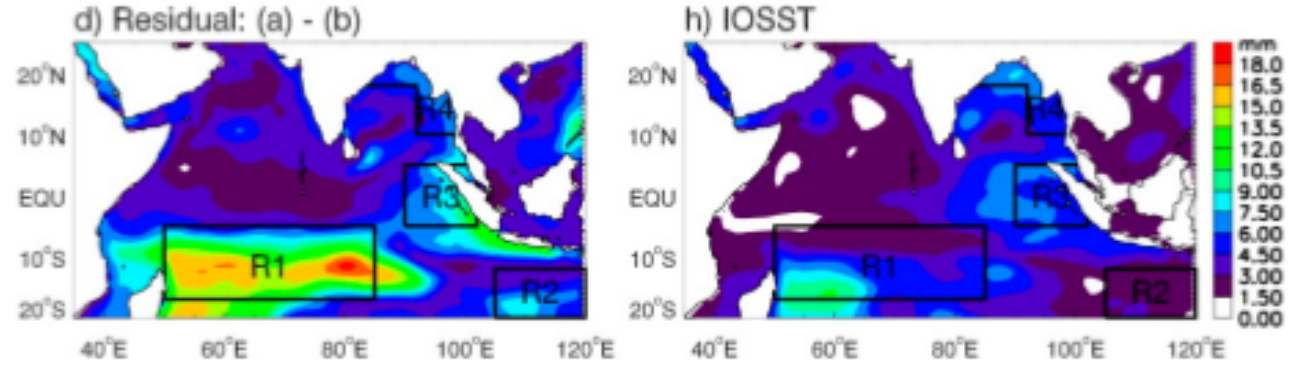

Figure 8. (a) The standard deviation map of the ORAS4 8 year low-passed SLA for the 1962-2011 period of the northern hemisphere summer season, based on the May-October averaged data of each year; (b) same as (a) but for SLA associated with all climate modes (ENSO + IOD + monsoon) plus the effect of IOSST which, to some extent, represents external forcing; (c) same as (b) but only for climate modes (ENSO + IOD + monsoon) and it equals the IOSST effect subtracted from panel (b); (d) same as (b) but for the residual, difference for $(\mathbf{a}, \mathbf{b})$, measuring the effects that cannot be explained by the climate modes and IOSST; (e-h) are the same as (b) but for the individual effect of decadal ENSO, IOD, monsoon, and IOSST. Units: $\mathrm{mm}$. The figure is the same as Figure 6 except for the northern summer. 
(b) Contribution to basin-wide EOF patterns. To reveal the dominant spatial patterns of decadal SLA, we carry out an EOF analysis for both winter and summer from 1962-2011. During winter, the leading EOF (EOF1; explaining 38\% variance) of ORAS4 SLA shows the falling sea level in the central and western basin with a maximum magnitude occurring in the Seychelles region, but rising sea level in the eastern basin with large amplitudes occurring near the ITF and coastal areas of the north IO (Figure 9a). This basin-wide pattern exhibits significant decadal variability, as shown by its principal component (PC1; the black curve of Figure 9d). Consistent with the STD analysis (Figure 7), the EOF1 of SLA from the sum of climate modes plus IOSST can reasonably represent the observed EOF1 pattern and its temporal evolution (Figure 9a,b), with the correlation between their PCs being 0.94 (Figure 9d); the climate modes account for most of the variability (Figure 9c,d), with decadal ENSO and monsoon (to a lesser degree) having large contributions, and the influence of decadal IOD being weak near the eastern IO coasts.

\section{EOF1: 8yrlp ORAS4 sla (mm)\& those due to climate modes, novapr}
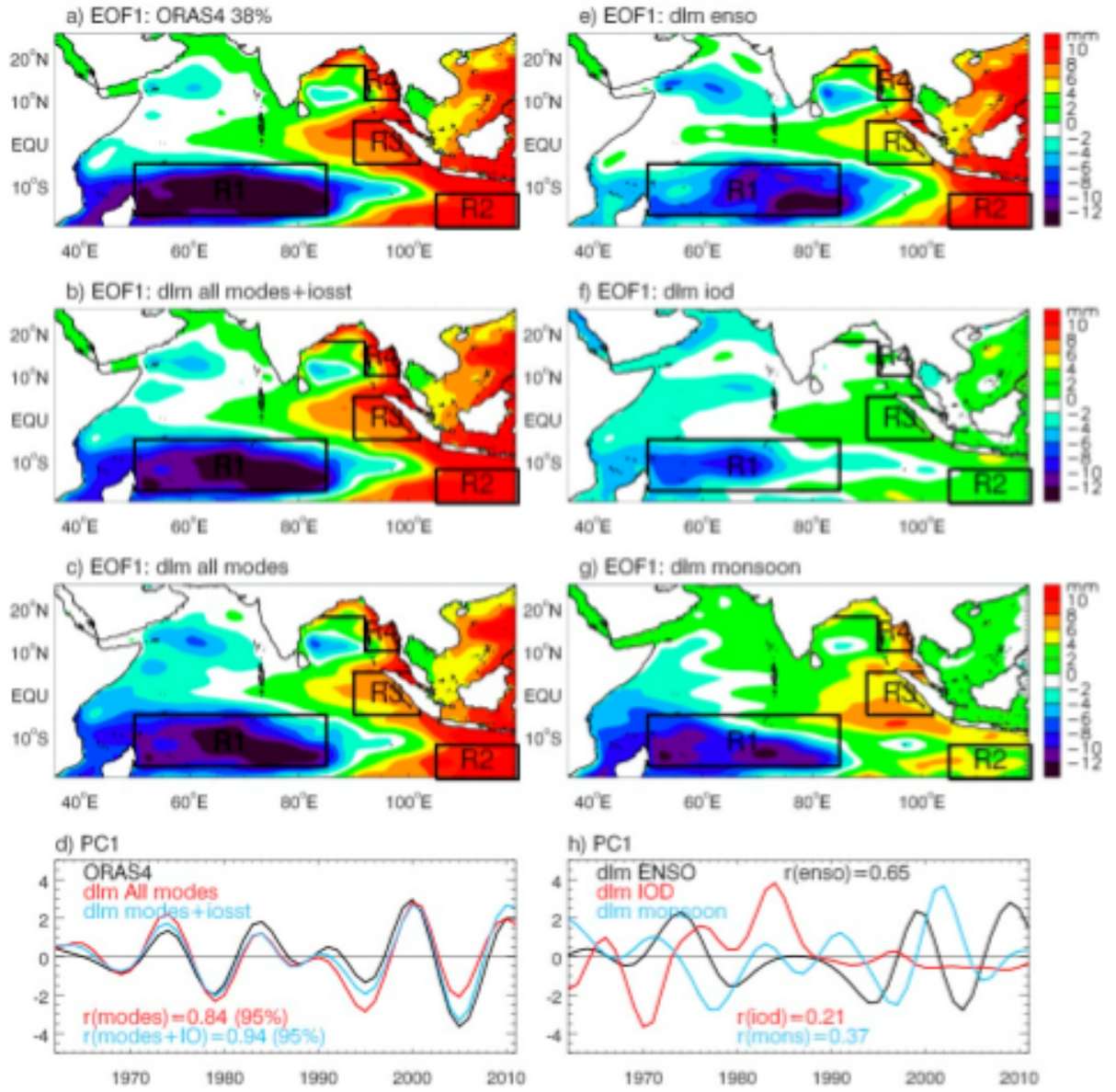

Figure 9. The leading Empirical Orthogonal Function (EOF1) of the 8 year low-passed November-April mean SLA over the tropical Indian Ocean for the period of 1962-2011 from (a) ORAS4 data; (b) Bayesian DLM simulation from the sum of all modes and IOSST (ENSO + IOD + monsoon + IOSST); and (c) DLM simulation from all modes (ENSO + IOD + monsoon); (d) the principal component of EOF1 (PC1) for ORAS4 (black), all modes + IOSST (blue), and all modes (red); (e-g) are the same as (c) except for the DLM simulation from ENSO, IOD, and monsoon, respectively; (h) Same as (d) except for the PC1 of ENSO (black), IOD (red), and monsoon (blue). The correlation coefficients shown in $(\mathbf{d}, \mathbf{h})$ are with the observed ORAS4 PC1 (the black curve of panel (d)). 
During summer, similar EOF1 patterns are found from observations (Figures 9a and 10a), and the total effect of the climate modes plus IOSST can still explain a large fraction of the basin-wide pattern. Similar to the STD analysis (Figure 8), climate modes plus IOSST explain less SLA variance in the eastern IO coastal regions compared to winter (Figure 10a-c) and the correlations between the observed and DLM simulated PC1s are 0.72 for climate modes plus IOSST and 0.50 for climate modes, which are significantly lower than the 0.94 and 0.84 of winter. The effect of decadal ENSO is confined to the south IO (Figure 10e), and decadal IOD is important for causing the SLAs along the coasts of the Sumatra and Bay of Bengal (Figure 10f). Different from the STD analysis, monsoon variability plays a larger role than IOD in determining the observed EOF1 pattern and its temporal evolution (Figure 10g,h). The dominance of decadal IOD in causing the regional SLAs near the coasts of Sumatra and Bay of Bengal (Figure 8) is not reflected in the EOF1s and PC1s, although the EOF2 of the IOD-associated SLA does show the strongest variability along the eastern IO coasts compared to ENSO and monsoon (not shown). Indeed, the EOF1 of climate modes essentially fails to capture the strong SLA along the coasts of Sumatra and Bay of Bengal (compare Figure 10a,c), even though the effect of IOSST improves this situation (Figure 10b). These differences arise from the fact that the basin-wide EOF1 patterns may not properly capture the regional/local features of the climate modes' impacts shown in the STD maps.

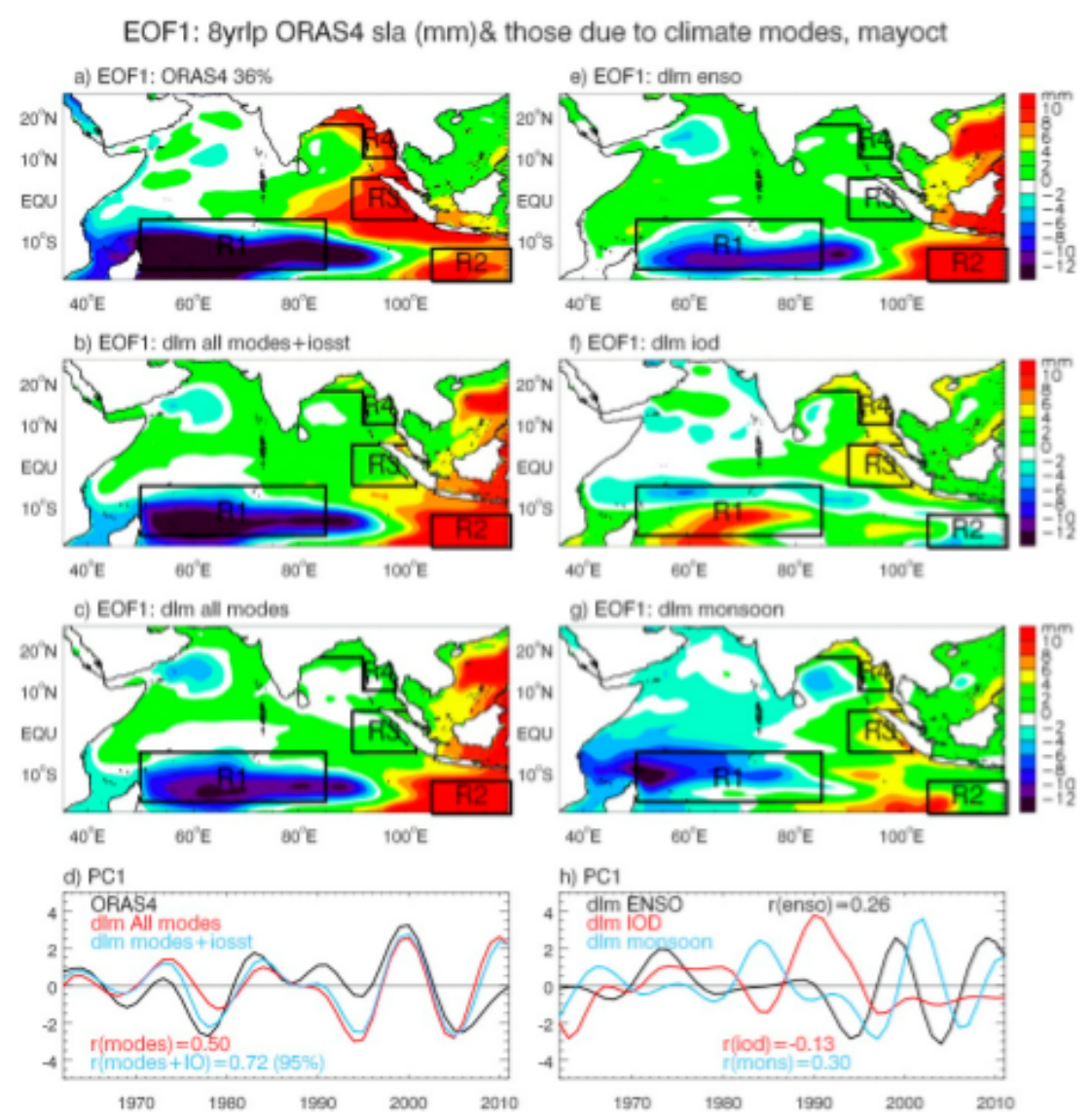

Figure 10. The EOF1 of the 8 year low-passed May-October mean SLA over the tropical Indian Ocean for the period of 1962-2011 from (a) ORAS4 data; (b) DLM simulation from the sum of all modes and IOSST (ENSO + IOD + monsoon + IOSST); and (c) DLM simulation from all modes (ENSO + IOD + monsoon); (d) PC1 for ORAS4 (black), all modes + IOSST (blue) and all modes (red); (e-g) are the same as (c) except for the DLM simulation from ENSO, IOD, and monsoon, respectively; (h) same as (d) except for the PC1 of ENSO (black), IOD (red), and monsoon (blue). The correlation coefficients shown in (d,h) are with the observed ORAS4 PC1 (the black curve of panel (d)). This figure is the same as Figure 9 except for the northern summer (May-October mean). 
(c) Time series analysis. To quantify the temporal evolution of the climate modes' impacts on regional SLA, we analyze the time series of decadal SLA averaged for each of the four key areas shown in Figures 6-10 where the SLA STDs are large. During winter, the results of Bayesian DLM show that the STD ratios between climate-modes-associated and observed SLAs (thin and thick solid curves of Figure 11 ) are $78 \%, 86 \%, 84 \%$, and $80 \%$, and their correlations are $0.80,0.89,0.87$, and $0.85(>95 \%)$ in Reg. 1, 2,3, and 4, respectively. Adding the IOSST effect to the climate modes (green and black solid curves of Figure $9 \mathrm{a}-\mathrm{d}$ ), the STD ratios increased to $83 \%, 92 \%, 93 \%$, and $91 \%$ and the correlations to $0.87,0.96,0.95$, and 0.94 , indicating that the external forcing has improved the STD ratios by $5-11 \%$ in Regs. $1-4$. The 5-6\% values in Regs. 1-2 are smaller than the external forcing of $17-18 \%$ estimated from the total of MPI + CESM1 relative to the average of the ORAS4 and SODA data (Figure 5; Section 3.2.1). This is expected, given that the IOSST may only partly reflect the effect of the external forcing since the 1980s (Section 2.4). Decadal ENSO is the largest contributor in all regions (the right column of Figure 11) and it is the controlling factor for the ITF area (Figure 11d). The effects of the decadal monsoon are also strong in all regions except for near the ITF, but their values are systematically weaker than that of decadal ENSO. The influence of IOD is relatively weak, with the largest effect (STD ratio of $\sim 30 \%$ to observation) occurring over the Seychelles region.

During summer (Figure 12), the climate modes explain a lower percentage variance of the observed SLA in all regions (Reg. 1, 3, and 4) except for the ITF area (Reg. 2). Over Seychelles, the Sumatra coasts, and the Bay of Bengal coasts, the STD ratios between the climate modes-associated and observed SLAs are $67 \%, 58 \%$, and $63 \%$ with $r=0.76,0.86$, and 0.86 , respectively. Adding IOSST increases the STD ratios to $73 \%, 75 \%$, and $82 \%$ and correlation to $0.81,0.93$, and 0.95 . Near the ITF, however, the climate modes contribute to 95\% of the observed STD with $r=0.95$, which are higher than their corresponding winter values.

While ENSO remains the largest contributor to decadal SLA over Seychelles, the Indian summer monsoon and, to a lesser extent, the IOD also have significant contributions in this region (Figure 12b). Indeed, the effect of decadal monsoon is comparable to that of decadal ENSO in the past decade or so, with an SLA STD being $9.5 \mathrm{~mm}$ due to the monsoon and $9.7 \mathrm{~mm}$ due to ENSO from 1997-2011. Consistent with Figure 8, decadal IOD is the largest contributor near the coasts of Sumatra and the Bay of Bengal overall from 1962-2011, and its STD is significantly larger than that of the decadal monsoon, with decadal ENSO being the least important (Figure 12f,h). Note, however, that decadal IOD has its strongest contribution from the late 1980s to early 1990s, and its influence is rather weak during other times (blue curves of Figure 12f,h). In contrast, the effect of the monsoon is the largest in the past decade or so, with SLA STD being $8.8 \mathrm{~mm}$ and $7.8 \mathrm{~mm}$ in Reg. 3 and Reg. 4, compared to the IOD contribution of $2.3 \mathrm{~mm}$ and $2.1 \mathrm{~mm}$ for 1997-2011. The increased influence of the monsoon on coastal SLAs in the past decade will be further discussed in Section 3.3. As for winter, decadal ENSO plays a deterministic role in causing SLA near the ITF region, with the monsoon also being important in the recent decade (Figure 12d). The effect of the IOD and IOSST are weak. 


\section{Timeseries of regional-mean 8yrlp SLA $(\mathrm{mm}):$ 1962-2011 novapr}

a) Reg. 1 (ORAS4 \& modes)

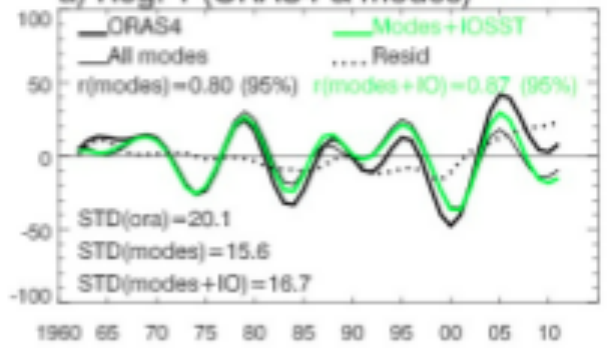

c) Reg. 2 (ORAS4 \& modes)

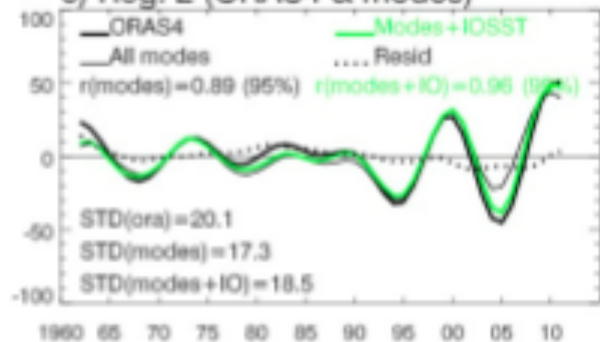

e) Reg. 3 (ORAS4 \& modes)

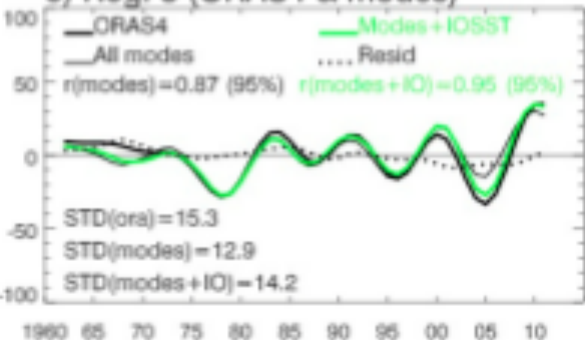

g) Reg. 4 (ORAS4 \& modes)

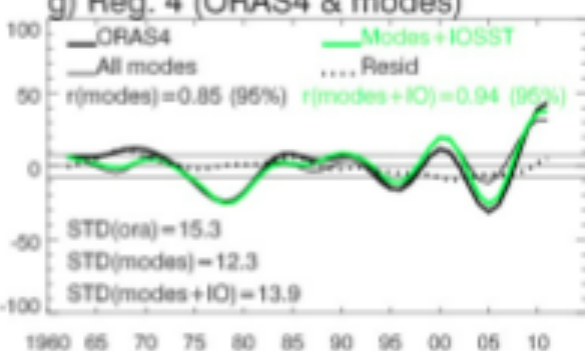

b) Reg. 1 (Individual mode)

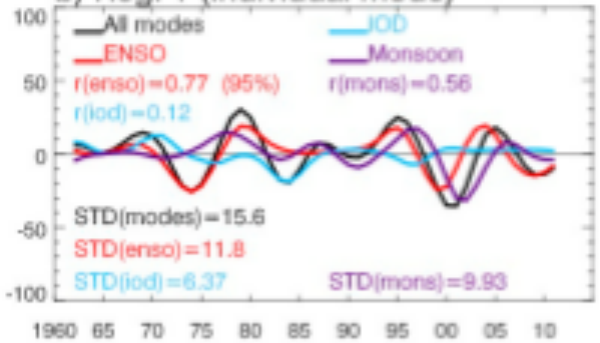

d) Reg. 2 (Individual mode)

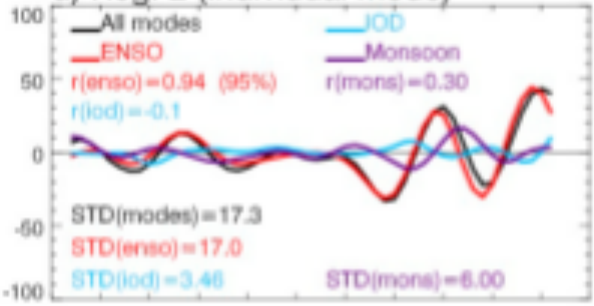

$\begin{array}{lllllllllll}1960 & 65 & 70 & 75 & 80 & 85 & 90 & 95 & 00 & 05 & 10\end{array}$

f) Reg. 3 (Individual mode)

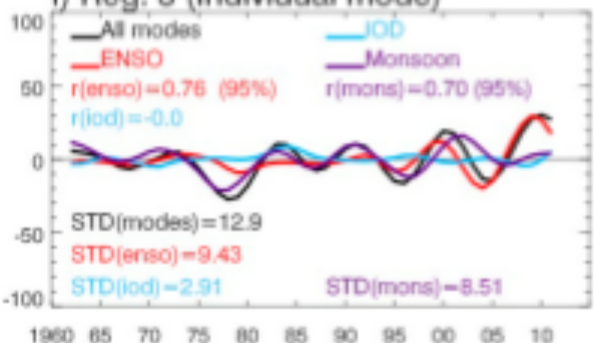

h) Reg. 4 (Individual mode)

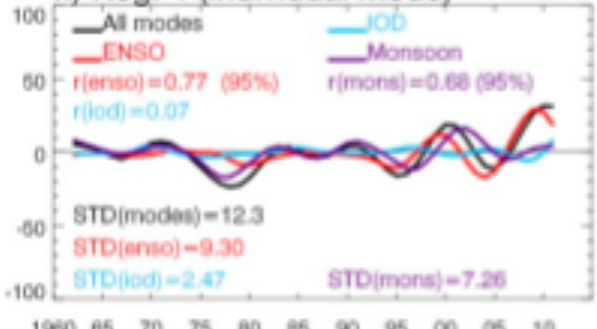

Figure 11. (a) The November-April averaged time series of the 8 year low-passed SLA averaged in the thermocline ridge region (Reg. 1 of Figures 6-10) from 1962-2011 from ORAS4 (thick solid black), the sum of climate modes' effects (ENSO + IOD + monsoon; thin solid black), all modes plus IOSST (green), and residual (black dotted), which is (ORAS4 - (all modes + IOSST)); linear trend for 1962-2011 is removed from each curve; (b) same as (a) except for contributions from all modes (black), decadal ENSO (red), decadal IOD (blue), and decadal monsoon (purple); panels (c-h) are the same as $(\mathbf{a}, \mathbf{b})$ except for the ITF area (Reg. 2 of Figures 6-10), eastern equatorial basin (Reg. 3 of Figures 6-10), and the Bay of Bengal coasts (Reg. 4 of Figures 6-10), respectively. The correlation coefficients $r$ in each panel of the left column are between the observed and DLM simulated SLA from climate modes (black) and climate modes + IOSST (green), and those in the right column show the $r$ between each climate mode and the sum of all climate modes. The two horizontal lines in (a) show the \pm 0.5 STD of the ORAS4 observed SLA, which serve as a reference for the composites of Section 3.3 below. 


\section{Timeseries of regional-mean 8yrlp SLA $(\mathrm{mm}):$ 1962-2011 mayoct}

a) Reg. 1 (ORAS4 \& modes)

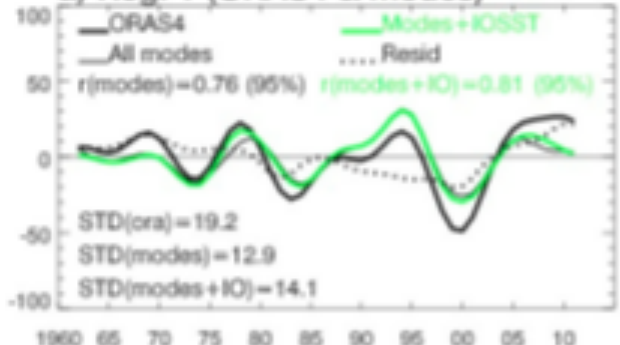

c) Reg. 2 (ORAS4 \& modes)

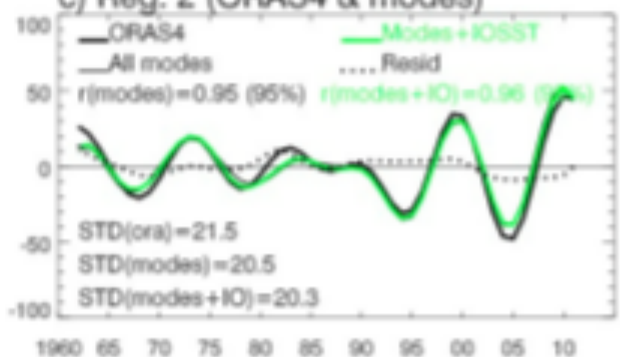

e) Reg. 3 (ORAS4 \& modes)

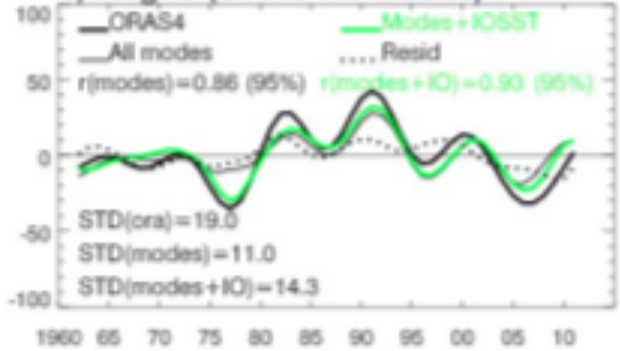

g) Reg. 4 (ORAS4 \& modes)

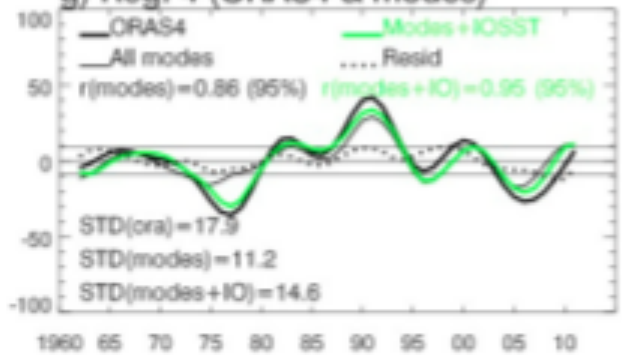

b) Reg. 1 (Individual mode)

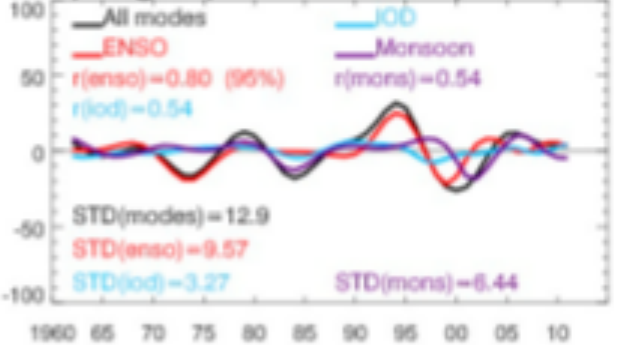

d) Reg. 2 (Individual mode)

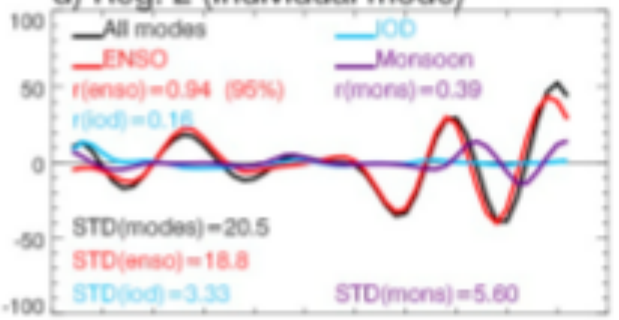

$\begin{array}{lllllllllll}1960 & 65 & 70 & 75 & 90 & 86 & 90 & 96 & 00 & 05 & 10\end{array}$

f) Reg. 3 (Individual mode)

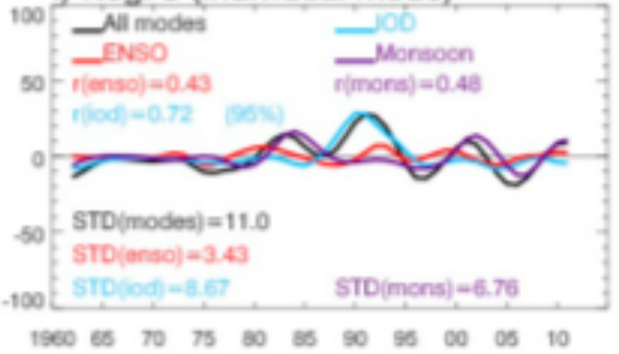

h) Reg. 4 (Individual mode)

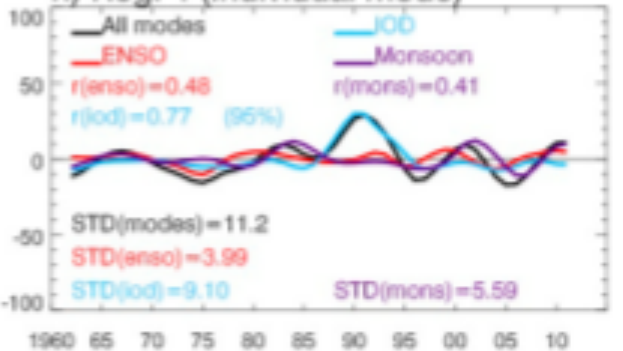

Figure 12. (a) The May-October averaged time series of the 8 year low-passed SLA averaged in Reg. 1 of Figures 6-10 from 1962-2011 from ORAS4 (thick solid black), the sum of climate modes' effects (ENSO + IOD + monsoon; thin solid black), all modes plus IOSST (green), and residual (black dotted), which is (ORAS4 - (all modes + IOSST)]; the linear trend for 1962-2011 is removed from each curve; (b) same as (a) except for the contributions from all modes (black), decadal ENSO (red), decadal IOD (blue), and decadal monsoon (purple); panels (c-h) are the same as (a,b) except for the ITF area (Reg. 2 of Figures 6-10), eastern equatorial basin (Reg. 3 of Figures 6-10), and Bay of Bengal coasts (Reg. 4 of Figures 6-10), respectively. The correlation coefficients $r$ in each panel of the left column are between the observed and DLM simulated SLA from climate modes (black) and climate modes + IOSST (green), and those in the right column show the $r$ between each climate mode and the sum of all climate modes. The two horizontal lines in (g) show the \pm 0.5 STD of ORAS4 observed SLA, which serve as a reference for the composites of Section 3.3. The figure is the same as Figure 11 except for the northern summer. 


\subsection{Influences of Winds Associated with Climate Modes}

To understand the effects of winds in driving the regional distributions of decadal sea level variability, we carry out composite analyses for decadal SLA, together with their associated surface wind stress and Ekman pumping velocity, defined as $w_{e}=\frac{\partial}{\partial x}\left(\frac{\tau^{y}}{\rho f}\right)-\frac{\partial}{\partial y}\left(\frac{\tau^{x}}{\rho f}\right)$, where $\tau^{x}$ and $\tau^{y}$ are zonal and meridional wind stress, $\rho=1000 \mathrm{~kg} \mathrm{~m}^{-3}$ is the mean water density, and $f$ is the Coriolis parameter. The composites are calculated for both the winter and summer seasons (Figures 13 and 14). For the November-April winter season, the years for the composite are chosen when the sea level fall (that is, the negative SLA) over Seychelles exceeds -0.5 STD in the ORAS4 data (Reg. 1, Figure 11a); for the May-October summer season, the years of the composite are chosen when the sea level rise (that is, positive SLA) adjacent to the Bay of Bengal coasts exceeds +0.5 STD (Reg. 4, Figure 12g). The criteria of the -1 STD are also tested and they yield similar results except for larger magnitudes for each field (not shown).

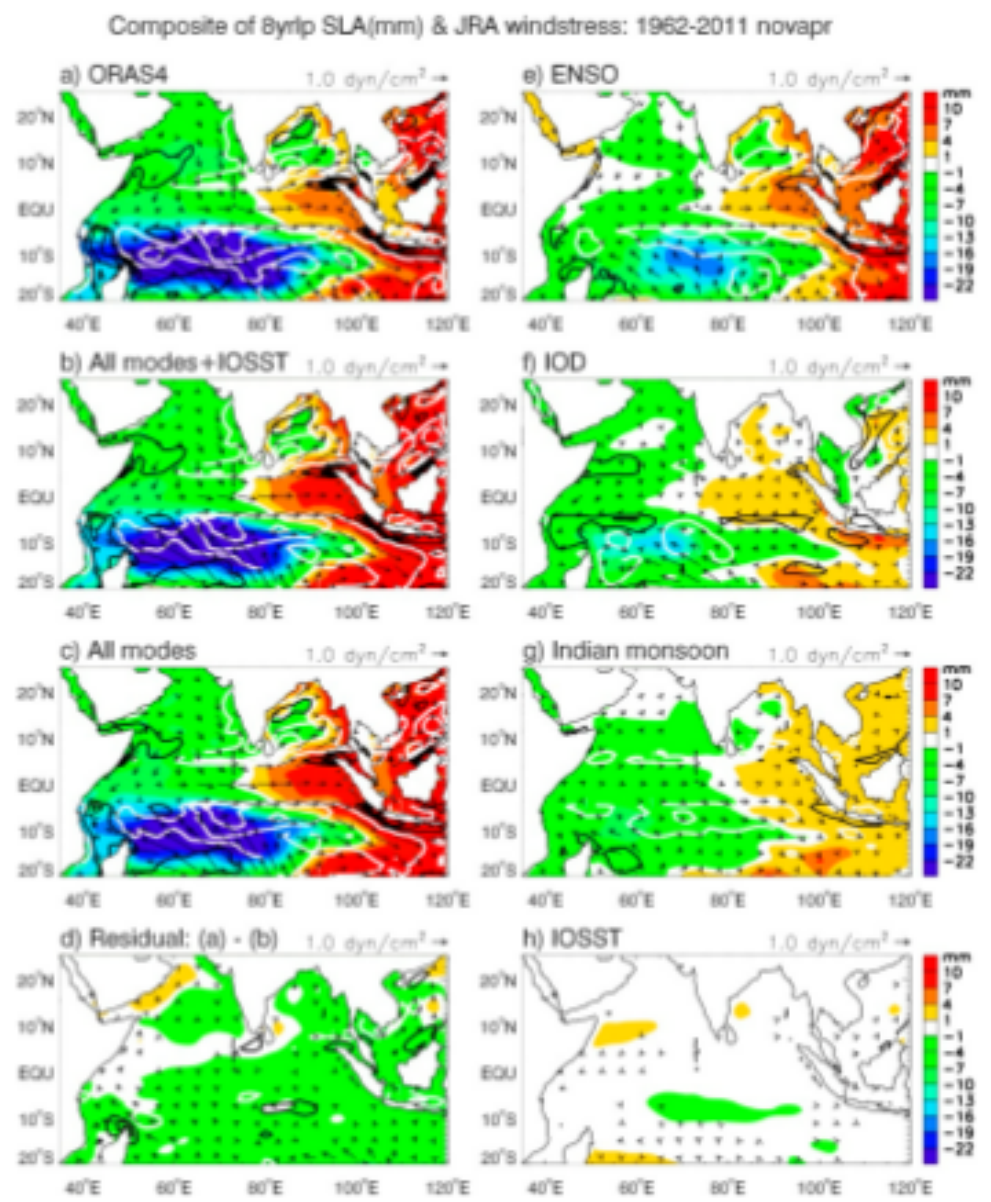

Figure 13. The composite analyses for the November-April mean, 8 year low-passed decadal SLA of November-April mean (color contours), the Japan Meteorological Agency 55-year Reanalysis (JRA55) surface wind stress (arrows; units: $\times 0.2{\mathrm{dyn} \mathrm{cm}^{-2}}^{-}$), and the Ekman pumping velocity, $w_{e}$ (line contours, positive (negative) values are in white (black), beginning at $1(-1)$ with an interval of 2; zero contours are omitted; units: $\times 10^{-7} \mathrm{~m} \mathrm{~s}^{-1}$ ), based on the years when the magnitudes of the ORAS4 decadal SLA in the thermocline ridge area (Reg. 1 of Figures 6-10) exceeded the -0.5 STD line shown in Figure 11a for: (a) the total SLA and wind anomalies; (b) the sum of the DLM results from all modes plus IOSST; (c) the sum of the DLM results from all modes; (d) the residual, which is panel (a) minus panel (b); $(\mathbf{e}-\mathbf{h})$ are the same as (c) but for the individual mode ENSO, IOD, monsoon, and IOSST, respectively. Note that the $w_{e}$ values within $5^{\circ} \mathrm{S}-5^{\circ} \mathrm{N}$ are not shown. 
Composite of 8yrlp SLA(mm) \& JRA windstress: 1962-2011 mayoct
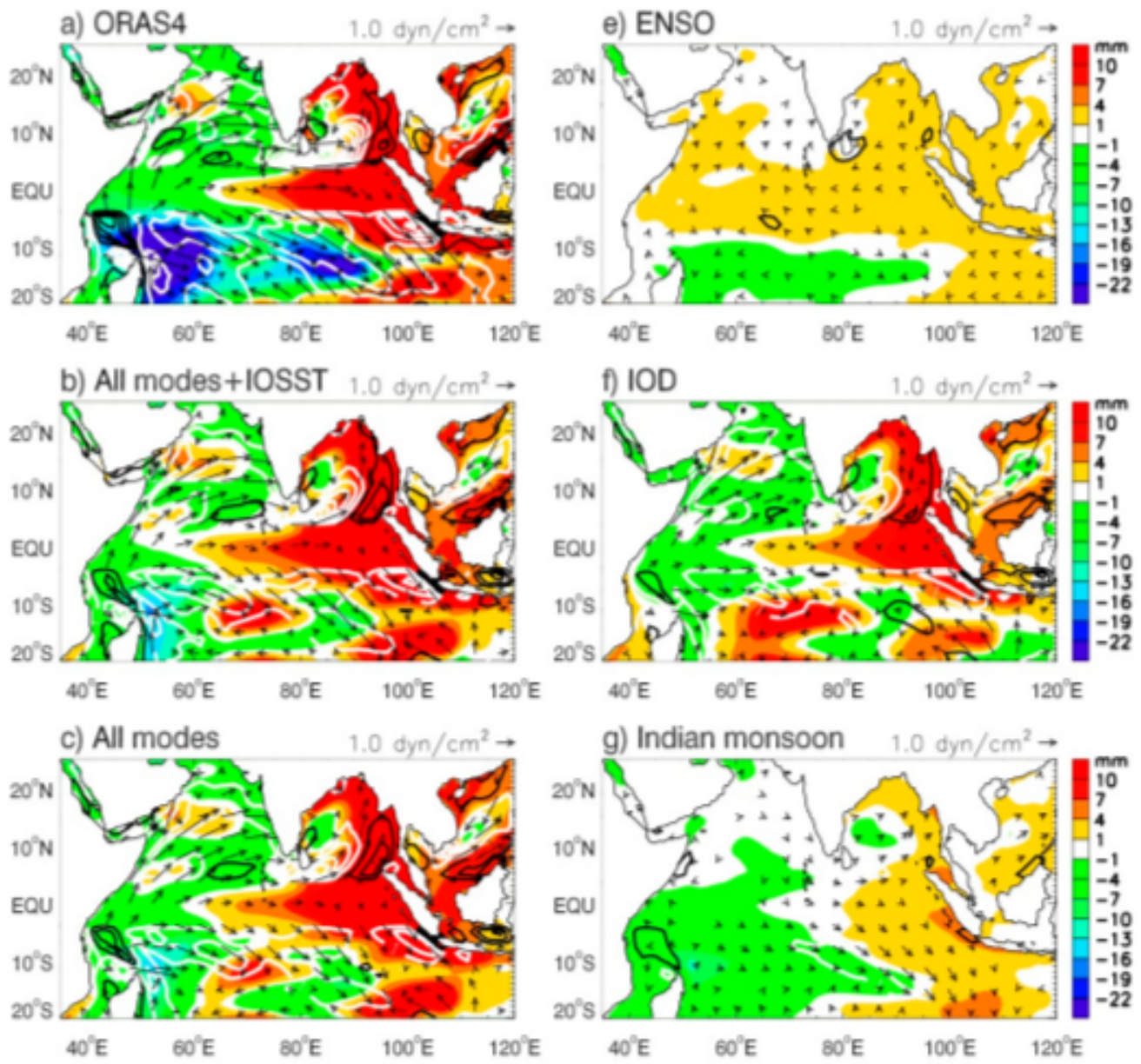

d) Residual: (a) - (b) $1.0 \mathrm{dyn} / \mathrm{cm}^{2} \rightarrow$

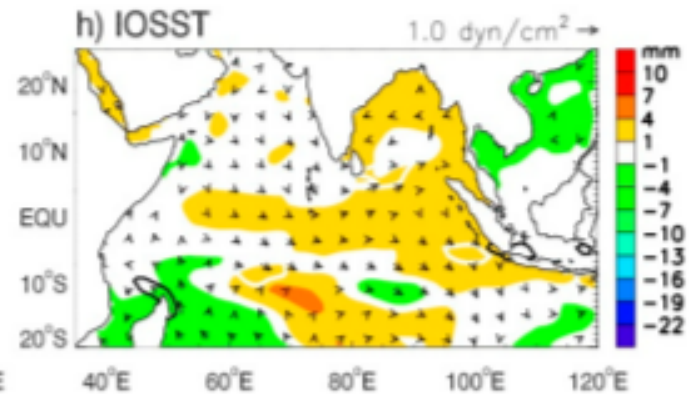

Figure 14. The composite analyses for the May-October mean, 8 year low-passed decadal SLA (color contours), the JRA55 surface wind stress (arrows; units: $\times 0.2 \mathrm{dyn}^{-2}$ ), and the Ekman pumping velocity, $w_{e}$ (line contours, positive (negative) values are in white (black), beginning at $1(-1)$ with an interval of 2; zero contours are omitted; units: $\times 10^{-7} \mathrm{~m} \mathrm{~s}^{-1}$ ), based on the years when the SLA values in the eastern Bay of Bengal (Reg. 4 of Figures 6-10) exceeded the +0.5 STD line shown in Figure 12g for: (a) the total SLA and wind anomalies; (b) the sum of the DLM results from all modes plus IOSST; (c) the sum of the DLM results from all modes; (d) the Residual, which is panel (a) minus panel (b); $(\mathbf{e}-\mathbf{h})$ are the same as (c) but for the individual mode ENSO, IOD, monsoon, and IOSST, respectively. The $w_{e}$ values within $5^{\circ} \mathrm{S}-5^{\circ} \mathrm{N}$ are omitted.

During winter, the composite SLAs show a basin-scale pattern that resembles EOF1 (Figures 9a and 13a). The positive Ekman pumping velocity $w_{e}$ in the south tropical IO (white contours of Figure 13a) drives surface mass divergence, lowering sea level and enhancing the upwelling of colder 
subsurface water into the surface. The colder water is denser and, thus, further lowers the sea level. Dynamically, the decadal SLAs are associated with the zonal integral of $w_{e}$ and on decadal timescales, the sea level variability of the tropical IO is in quasi-equilibrium with the wind forcing (Section 2.5). As a result, the amplitude of the sea level fall intensifies toward the west when $w_{e}$ keeps the same positive sign, attaining its maximum over Seychelles, but weakens near the western boundary where $w_{e}$ changes from positive to negative (black contours).

Near the equator, westerly wind anomalies cause surface Ekman convergence and raise the sea level. The high sea level signals propagate eastward as the equatorial Kelvin waves and then poleward along the eastern boundary as coastal Kelvin waves, increasing the sea level in the eastern equatorial basin and along the coasts of Sumatra, Java, and the Bay of Bengal (Figure 13a, color contours). Subsequently, the positive SLAs along the eastern boundary radiate westward as Rossby waves, weakened by the negative SLAs induced by the positive $w_{e}$ in the basin interior (for example, white contours over the Bay and in the south IO). Along the Sumatra and Java coasts, the negative $w_{e}$ induces Ekman convergence, which further increases the sea level in these regions. Over the Bay of Bengal, however, the local alongshore winds and $w_{e}$ are weak near the coasts; therefore, the coastal SLAs result mainly from the remote, equatorial wind forcing. The transient wave processes over the equatorial and north IO occur at timescales shorter than eighteen months [80,97] (Section 2.5). Consequently, the decadal SLAs are in equilibrium with decadal winds. Friction and the topographic beta effect associated with continental shelf, however, will trap part of the Rossby wave energy to the eastern boundary [98], contributing to the observed decadal SLAs near the coastal regions. The effects of topographic trapping and friction cannot be quantified by observational analyses, and high-resolution model experiments are needed to quantify these effects.

To extract the surface winds associated with climate modes, we apply the Bayesian DLM Equations (3)-(5) to the 8 year low-passed JRA55 winds. Like sea level, the decadal variations of surface winds also result mainly from climate modes (Figure 13a-d), with ENSO being the primary contributor during winter (Figure 13e). The influences of winds associated with monsoon and IOD are also evident, except that the IOD contributes little to the coastal SLAs in the Bay of Bengal, and the effect of IOSST is weak (Figure $13 \mathrm{f}-\mathrm{h}$ ).

Similar to winter, the composite analyses of summer show the deterministic role of surface winds in driving the IO regional SLAs, with the positive $w_{\mathrm{e}}$ accounting for the negative SLAs over Seychelles, and equatorial winds inducing increased sea level in the eastern basin (Figure 14a). The local $w_{\mathrm{e}}$ also enhances the SLA along the coasts of Sumatra and Java. Different from winter, the local alongshore wind and negative $w_{\mathrm{e}}$ near the eastern boundary of the Bay also enhance the positive SLAs around the perimeter of the Bay. Climate modes plus IOSST explain a large fraction of the SLA and wind (Figure 14a-c); the residual, however, is much larger than that of winter (Figures $13 \mathrm{~d}$ and $14 \mathrm{~d}$ ). The IOD-associated wind is the major cause for the coastal SLAs of Sumatra and the Bay of Bengal, and the effect of Indian summer monsoon wind is also evident but apparently weaker in the composite (Figure 14f,g) compared to its effect shown in the time series (Figure 12). This is because during the composite years of 1993 and 1999-2001, the decadal SLAs induced by monsoon were weak (Figure 12f,h), even though the monsoon convection plays a dominant role during the past decade. The influence of ENSO is relatively weak (Figure 14e), but the effect of IOSST is stronger compared to winter (Figures $13 \mathrm{~h}$ and $14 \mathrm{~h}$ ).

The vital role played by equatorial winds, together with the increased importance of the monsoon in the past decade, agrees well with the results of Han et al. (2017) [33], who showed that decadal variability of the Indian Walker Cell, measured by its surface branch of the zonal wind in the equatorial IO, was determined primarily by decadal variations of the Indian summer monsoon since the late 1990s [33]. A thorough understanding of the non-stationary impacts of climate modes and their causes on the IO regional, decadal SLA is beyond the scope of this paper, but it will be investigated in our future research. 
Near the ITF area, $w_{e}$ anomalies are positive during both winter and summer, yet decadal SLAs are strong and positive (Figures $13 \mathrm{a}$ and 14a), suggesting that the $w_{e}$ anomalies are not the cause of the positive SLAs. While the strong variability of zonal equatorial winds and local alongshore winds near the northwest Australian coast may contribute to the decadal SLAs in Reg. 2 via coastal Kelvin and westward radiating Rossby waves, the remote forcing from the Pacific via the ITF can have a strong influence in this region (see Section 1). This is supported by the vital role of the decadal ENSO in determining the SLAs in this area for both seasons (Figures $11 \mathrm{~d}$ and $12 \mathrm{~d}$ ).

To further confirm the composite SLA and surface wind patterns obtained from ORAS4 and JRA55 reanalyses, we compare them with satellite-observed AVISO SLA and CCMP1 winds for their overlapping period of 1993-2011 (Figure 15). First, the composite SLA and surface winds using ORAS4 and JRA55 data for 1998-2002 (Figure 15a), the five years when the November-April mean decadal SLAs exceeded the -0.5STD in Reg. 1 within the 1993-2011 period and resembled those of 1962-2011 (Figure 13a), albeit with larger SLA amplitudes for the shorter 1993-2011 period (note the scale changes in the color bars of Figures 13a and 15a). The 1998-2002 composites based on the 8 year low-passed SLAs are similar to those based on the unfiltered fields, and they are also similar to the satellite-observed SLAs and surface winds (Figure 15a-c). The surface wind anomalies are tied to the anomalous tropical deep convection and precipitation, converging to the increased convection (negative OLR) and precipitation over the Indo-Pacific warm pool and diverging from the reduced convection (positive OLR) and precipitation in the tropical southwest basin and northern IO (color and line contours of Figure 15d).

\section{Composite of SLA $(\mathrm{mm})$, wind, OLR and precip. for years within 1993-2011}

a) Nov-Apr: ORAS4 \& JRA55 8yrip

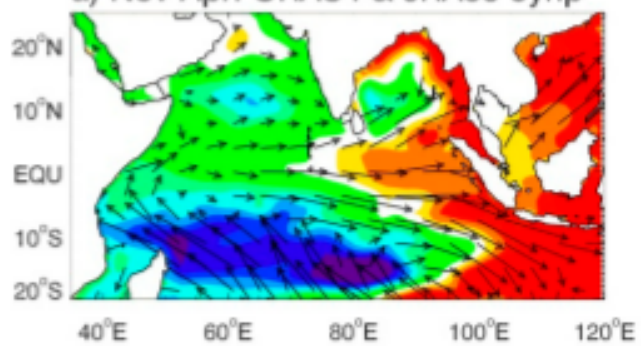

b) Nov-Apr: ORAS4 \& JRA55

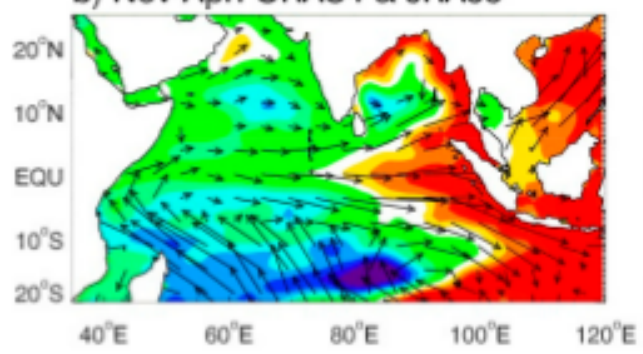

c) Nov-Apr: AVISO \& CCMP

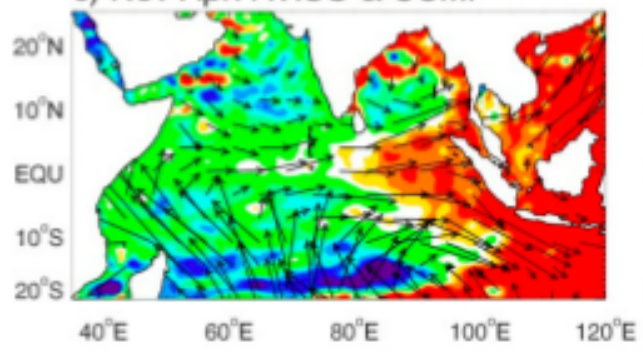

e) May-Oct: ORAS4 \& JRA55 8yrlp

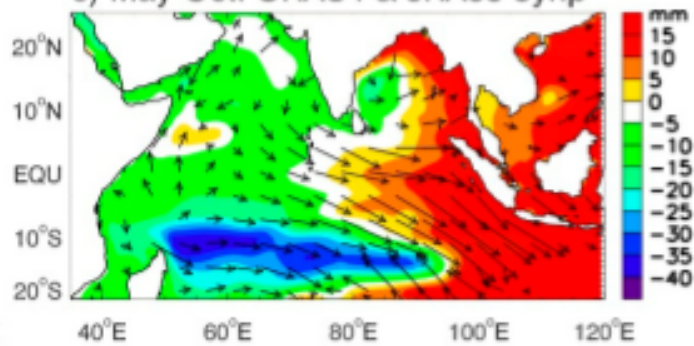

f) May-Oct: ORAS4 \& JRA55

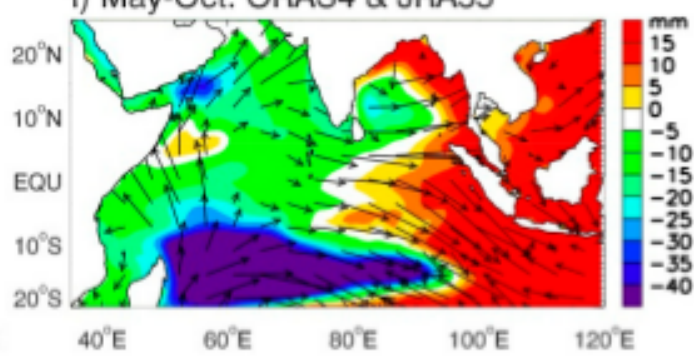

g) May-Oct: AVISO \& CCMP

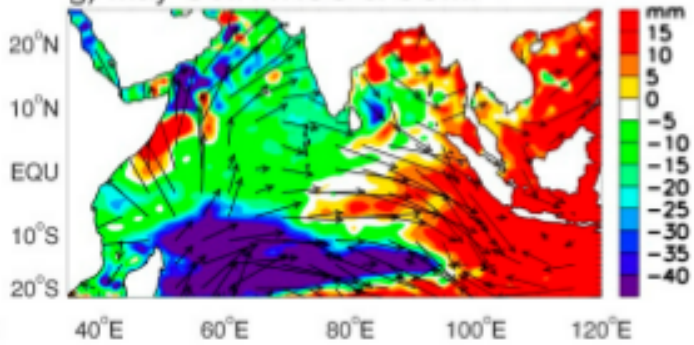

Figure 15. Cont. 

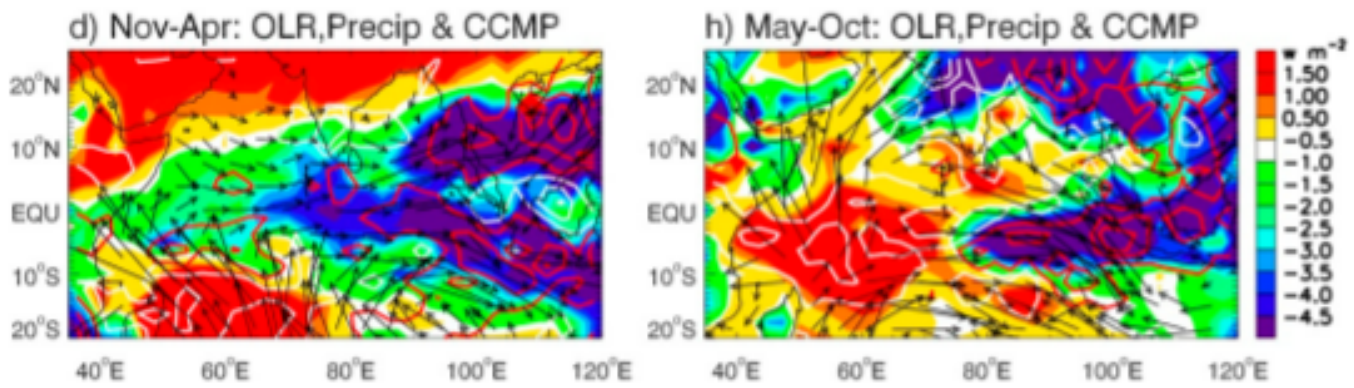

Figure 15. (a) The composite for the November-April mean, 8 year low-passed ORAS4 SLA (color contours), and the JRA55 surface wind stress (arrows; units: $\times 0.2 \mathrm{dyn}^{-2}$ ) for years 1998-2002 when the magnitudes of ORAS4 SLA of Reg. 1 (Figures 6-10) exceeded -0.5 STD (see Figure 11a); it is the same as Figure 13a except for the years within 1993-2011 when all the datasets are available; linear trend for 1993-2011 is removed from each field; (b) same as (a) but with no lowpass filtering; (c) same as (b) but for the AVISO SLA and cross-calibrated multiplatform (CCMP) satellite winds with no filtering; (d) same as (c) but with color contours showing the Outgoing Longwave Radiation (OLR) anomaly (white (red) line contours showing the Global Precipitation Climatology Project (GPCP) negative (positive) precipitation anomaly, beginning at $\pm 0.2 \mathrm{~mm} \mathrm{day}^{-1}$ with an interval of 0.4 ; the zero contour suppressed); the OLR and precipitation anomalies are shown over both ocean and land; panels (e-h) are the same as (a-d) except for the May-October mean composites for years 1993 and 1999-2001 when the magnitudes of ORAS4 decadal SLA of Reg. 4 exceeded +0.5STD (see Figure 12g).

Similarly, the filtered and unfiltered summertime composites of SLA and surface wind anomalies from reanalysis data, based on the four years of 1993 and 1999-2001 when ORAS4 SLA in Reg. 4 exceeded $+0.5 S T D$ (Figure 12d), agree well with the satellite observations (compare Figures 14a and $15 \mathrm{e}-\mathrm{g})$, and the surface wind patterns are closely tied to anomalous convection and precipitation, converging to (diverging from) the enhanced (reduced) convection and precipitation areas (Figure 15h). The increased convection and precipitation in the eastern equatorial basin and reduced convection and precipitation in the west agree with the negative IOD events, which are shown to be the dominant cause for the summertime increased SLAs along the coasts of Sumatra and the Bay of Bengal (Figure 14). Over the Indian subcontinent, convection and precipitation are also enhanced, indicating a stronger summer monsoon situation. However, whether or not the negative decadal IOD events always accompany enhanced decadal convection of Indian summer monsoon requires further investigation. The data record is too short to make a definitive conclusion, and the four-year composite may still contain some inter-annual variability.

While the increased convection in the warm pool reduces the downward shortwave flux and, thus, decreases the sea level through thermosteric effect, the increased precipitation tends to increase the sea level via halosteric effect. The opposing influence of shortwave flux and precipitation may partly account for the compensating effect of the thermal and halosteric sea level on regional scales discussed in Stammer et al. [5]. This compensation weakens the contribution of buoyancy flux to regional decadal SLA, which may further contribute to the dominance of winds in causing regional, decadal sea level variability over the IO.

\section{Summary and Discussions}

By analyzing observational datasets and the results from large ensemble experiments of two global climate models, we assessed the influences of natural internal variability versus external (natural plus anthropogenic) forcing on the observed multi-decadal trend patterns and decadal SLA in the tropical IO north of $20^{\circ} \mathrm{S}$ since the 1960s. Here, we focused on understanding the "regional trend pattern" and decadal SLA after removing the global mean SLR. Consequently, the significant effect of external forcing on the global mean SLR was removed before our analysis. Using Bayesian DLM, 
we quantified the influences of climate modes (that is, ENSO, IOD, and monsoon; Figure 1) on the IO regional, decadal SLA. The Bayesian DLM can capture the non-stationary impacts of climate modes on the regional sea level and, thus, it consistently outperforms the conventional multiple linear regression model in simulating the observations and in estimating the impacts of each climate mode [33] (Section 2.4). Our major findings are summarized below.

(1) For the 48-yr trend pattern of the sea level (with global SLR removed) from 1958-2005, natural internal variability dominates the external forcing in causing the spatially uneven sea level change patterns over the IO, with natural variability (external forcing) accounting for $\sim 81 \%(19 \pm 2.4 \%)$ of the observed falling trend over the Seychelles Islands where both the observed and externally forced trends obtain their maxima (Figure 2). These percentage values are obtained using the average of ORAS4 and SODA to represent the observation and the 100-member mean of the external forcing ensemble, with each member being the ensemble average of 98 members $(70 \%$ of 140) randomly chosen from the 140 members of the two climate models (100 from MPI and 40 from CESM1), to represent external forcing (Table 1; see Section 3.1 for detailed descriptions on the Monte Carlo method of assessing external forcing and uncertainty). This is because large quantitative or even qualitative differences exist in some regions between ORAS4 and SODA data and between the MPI and CESM1 results (Figures 2-4), even though both reanalysis data produce similar basin-wide patterns. The ORAS4 product agrees the best with the AVISO sea level since 1993 (pattern correlation $r=0.84)$ compared to SODA $(r=0.48)$ and the thermosteric sea level (Figure 3), likely due to the ORAS4 assimilated satellite-observed sea level data. The 100-member ensemble mean agrees well with the subsamples of the 40-member ensemble means of the MPI model, even though some quantitative differences remain in some regions. This suggests that 40-member ensemble averages can reasonably damp internal variability in the multi-decadal trend, and the large differences between the MPI and CESM1 simulations result from the model dependence of the sea level response to the same external forcing.

(2) For decadal variability, represented by 8 year low-passed SLA from 1962-2011 (both global SLR and regional trend removed), the largest contribution of external forcing (measured by the 1.65STD of the 100-member mean of the external forcing ensemble) is $18 \pm 17 \%$ of the observed SLA STD (ORAS4 and SODA average) in the Seychelles region and $17 \pm 11 \%$ in the southeastern basin near the ITF (Figures 4 and 5). Consequently, the observed decadal SLA results predominantly from natural internal variability. While the variances of the decadal SLA from the MPI and CESM1 reach large magnitudes in similar areas, the time series of their LE averaged decadal SLAs for the same areas differ considerably in amplitude and phase, showing weak or negative correlations. These results suggest that the decadal predictions and future projections of the regional sea level can be strongly model-dependent because they can respond very differently to the same external forcing on regional scales. Efforts should be made to understand the causes for the strong model-dependence and identify their biases, with a hope to improve the physical representations of processes in climate models, and ultimately improve their simulations, predictions, and future projections.

(3) Decadal SLAs exhibit distinct basin-wide patterns, with the sea level fall in the southwest tropical IO accompanying the sea level rise in the eastern basin (Figures 9 and 10). The strong decadal variability overlies on the multi-decadal falling trend in the western basin, but on the rising trend in the eastern basin, particularly in the coastal regions of Sumatra and the Bay of Bengal. This can increase the stress of SLR for coastal countries such as Bangladesh, whose elevation is near the sea level. Climate modes (the sum of decadal ENSO, IOD, and monsoon) explain a large fraction of the observed decadal sea level variability, regardless of whether the decadal SLAs are based on the annual (12-month) mean winter (November-April) or summer (May-October) seasons, and the impacts of the individual modes exhibit apparent seasonality (Figures 6-12). 
During November-April (Figure 11), the STD ratios between the climate-modes-associated and observed decadal SLAs are $\sim 80-86 \%$ and their correlation coefficients are $r=0.80-0.89(>95 \%$ significance) in the four key regions where the decadal SLAs are large, that is, the Seychelles Islands (Reg. 1), the ITF area (Reg. 2), west coasts of Sumatra (Reg. 3), and the east and north coasts of the Bay of Bengal (Reg. 4). The smallest impact occurs over Seychelles (78\% and $r=0.80)$ and the largest impact occurs near the ITF ( $86 \%$ and $r=0.89)$. Adding the IOSST, which represents part of the external forcing, increases the STD ratios to $>90 \%$ and $r$ to $\geq 0.94$ in all areas but the Seychelles, where the ratio increases to $83 \%$ and $r$ to 0.87 (Figure 11). The decadal ENSO is the largest contributor to the basin-wide pattern and individual areas in both the basin interior and along the coasts (Figures 7 and 9) and it controls the SLA near the ITF area. Decadal variability of the monsoon also has evident effects in all regions except for the ITF, and the influence of the decadal IOD is relatively weak, with its strongest effect occurring over Seychelles. The caveat for the weak IOD influence in the eastern IO coast during boreal winter is that part of the IOD impact is embedded in the effect of ENSO because we removed the ENSO signals from the DMI to ensure the independence of predictors in the DLM equations (Section 2.4). The removal of ENSO from the DMI implies that the ENSO affects IOD but IOD does not affect ENSO. Yet existing studies have suggested the active impact of IOD on ENSO. This procedure may, to some degree, overestimate the ENSO effect and underestimate the IOD effect (Section 3.2.2).

During May-October, the climate modes explain a lower percentage of the observed SLA variance compared to winter, both for the basin-wide EOF patterns and for the individual regions over Seychelles, Sumatra coasts, and Bay of Bengal coasts where the STD ratios between climate-modes-associated and observed SLAs are $67 \%, 58 \%$, and $63 \%$ and correlations are $r=0.76$, 0.86 , and 0.86 , respectively (Figures 8, 10 and 12). Adding IOSST increases the STD ratios to 73\%, $75 \%$, and $82 \%$ and the correlation to $0.81,0.93$, and 0.95 . An exception is for the ITF area where the total effects of the climate modes, which are higher than their corresponding winter values, explain 95\% of the observed STD with $r=0.95$. Decadal ENSO is the determining factor for the ITF area, with the decadal monsoon having a comparable contribution in the past decade or so (1997-2011). Over the Seychelles area, decadal ENSO is the largest contributor, with decadal monsoon also having considerable contributions particularly in the past decade. The effect of decadal IOD is also non-negligible. Along the coasts of Sumatra and the Bay, decadal IOD is the largest contributor overall from 1962-2011 and is the controlling factor from the end of the 1980s to early 1990s, while decadal monsoon is the largest contributor in the past decade.

(4) Decadal variability of the surface winds over the IO plays a vital role in causing decadal SLAs over most regions of the IO, except for the ITF area where the remote forcing from the Pacific via the ITF is also important. While the Ekman pumping velocity is the major cause for the large SLAs over the Seychelles Islands, the zonal equatorial wind anomalies associated with the Walker Circulation primarily determines the SLAs along the coasts of Sumatra, Java, and the Bay of Bengal for both the winter and summer seasons. The local Ekman pumping velocity near the Sumatra and Java coasts, together with the alongshore winds and Ekman pumping velocity in the eastern Bay during summer, enhance the SLA amplitudes in the coastal regions. These results, which are based on reanalysis data, are supported by the AVISO satellite sea level and CCMP winds for their overlapping periods during recent decades. In addition, satellite-observed convection (that is, OLR) and GPCP precipitation further confirm the wind variations, and they also suggest a compensating effect of thermosteric and halosteric sea level. This is because in regions of increased convection and precipitation, such as the western equatorial IO associated with $+\mathrm{IOD}$, the reduction in the shortwave flux and upper ocean temperature act to decrease thermosteric sea level; meanwhile, the increased precipitation increases the halosteric sea level. This compensation weakens the total effect of buoyancy forcing on regional, decadal SLA. Topographic trapping of the Rossby wave energy by the continental shelf along the west Australian coast [98], together with frictional damping of coastal Kelvin and Rossby waves will 
also affect coastal SLA. These coastal effects will be investigated in our future research using high-resolution numerical models.

Even though the record length of $\sim 50$ year is relatively short, our results from the observational analysis using Bayesian DLM may, to a certain degree, serve as a benchmark for verifying the skills of global climate models in simulating climate modes and their associated decadal sea level patterns over the Indian Ocean. Note that the positive skill of decadal predictions in the first few years results from the observation-based initialization $[41,42]$, which carries climate mode signals that evolve in time via air-sea coupling and interactions among different components of the climate system. Model biases and mean state drift, however, significantly limit the prediction of climate modes' evolution. For this reason, understanding the past sea level behaviors associated with climate modes, as is done in this paper, and using them to infer the near-future evolutions of regional sea level using advanced empirical methods, are as important as the efforts of improving the simulation skills of climate models. The two approaches should be explored in parallel to satisfy the short- and long-term societal needs of sea level predictions on regional scales.

Supplementary Materials: The following are available online at http:/ /www.mdpi.com/2225-1154/6/2/51/s1, which includes three supplementary figures. Figure S1: Bar graph for the ratios (\%) of linear trend and uncertainty of sea level from 1958-2005 between model ensemble mean and observation for the west Indian Ocean Seychelles area and east equatorial Indian Ocean (boxes of Figure 2); Figure S2: Time series of 8yr lowpass filtered decadal SLA $(\mathrm{mm})$ averaged over the Seychelles Island area in the west (Reg. 1 of Figure 4) and near the ITF area in the east (Reg. 2 of Figure 4) from observations and LE climate model simulations; Figure S3: Line plots of the STD of decadal SLA (from 1962-2011) for the 100-member ensemble mean (blue curves) versus the chosen number $(\mathrm{N})$ of ensemble members used in the Monte Carlo method for the MPI+CESM1 (140 members), MPI (100 members), and CESM1 (40 members), respectively, over the west Indian Ocean Seychelles area.

Author Contributions: W.H. carried out the analyses and wrote the paper; D.S., G.M. Additionally, A.H. contributed to the result interpretation and manuscript writing; A.H. prepared the outputs for the 40-member ensemble of the CESM1 model; F.S. processed, prepared and analyzed the outputs from the 100-member ensemble of the MPI model; L.Z. assessed and analyzed the uncertainties of the sea level variability.

Acknowledgments: The work was initiated when Weiqing Han was visiting the University of Hamburg during her sabbatical leave in summer 2016. She thanks DFG funded Excellent Cluster CliSAP of the University of Hamburg for providing financial support. Weiqing Han is supported by National Science Foundation (NSF) AGS 1446480, NSF OCE 1558736, NASA OSTST NNX17AI63G, and NASA OVWST NNX14AM68G. Detlef Stammer is supported in part through the German RACE project funded by the BMBF and the European NaCLIM project. This work contributes to the DFG funded Excellence Cluster CliSAP of the University of Hamburg. Gerald A. Meehl and Aixue Hu are partly supported by the Regional and Global Model Analysis Program (RGMA) of the U.S. Department of Energy's Office of Science (BER), Cooperative Agreement No. DE-FC02-97ER62402. The National Center for Atmospheric Research is sponsored by the National Science Foundation. Frank Sienz was supported by the Max-Planck Institute for Meteorology, Hamburg, Germany. We thank Jochem Marotzke for providing the MPI large-ensemble simulations, and Luis Kornblueh, Jürgen Kröger, and Michael Botzet for performing the MPI experiments. The CESM Large Ensemble Community Project and supercomputing resources were provided by NSF/CISL/Yellowstone.

Conflicts of Interest: The authors declare no conflict of interest.

\section{References}

1. Nicholls, R.J.; Cazenave, A. Sea-Level Rise and Its Impact on Coastal Zones. Science 2010, 328, 1517-1520. [CrossRef] [PubMed]

2. Neumann, B.; Vafeidis, A.T.; Zimmermann, J.; Nicholls, R.J. Future Coastal Population Growth and Exposure to Sea-Level Rise and Coastal Flooding-A Global Assessment. PLoS ONE 2015, 10. [CrossRef] [PubMed]

3. Milne, G.A.; Gehrels, W.R.; Hughes, C.W.; Tamisiea, M.E. Identifying the causes of sea-level change. Nat. Geosci. 2009, 2, 471-478. [CrossRef]

4. Church, J.A.; Clark, P.U.; Cazenave, A.; Gregory, J.M.; Jevrejeva, S.; Levermann, A.; Merrifield, M.A.; Milne, G.A.; Nerem, R.S.; Nunn, P.D.; et al. Sea Level Change. In Climate Change 2013: The Physical Science Basis. Contribution of Working Group I to the Fifth Assessment Report of the Intergovernmental Panel on Climate Change; Stocker, T.F., Qin, D., Plattner, G.-K., Tignor, M., Allen, S.K., Boschung, J., Nauels, A., Xia, Y., Bex, V., Midgley, P.M., Eds.; Cambridge University Press: Cambridge, UK, 2014; pp. 1137-1216. [CrossRef] 
5. Stammer, D.; Cazenave, A.; Ponte, R.M.; Tamisiea, M.E. Causes for Contemporary Regional Sea Level Changes. Annu. Rev. Mar. Sci. 2013, 5, 21-46. [CrossRef] [PubMed]

6. Kopp, R.E.; Horton, B.P.; Kemp, A.C.; Tebaldi, C. Past and future sea-level rise along the coast of North Carolina, USA. Clim. Chang. 2015, 132, 693-707. [CrossRef]

7. Mccreary, J.P.; Kundu, P.K.; Molinari, R.L. A Numerical Investigation of Dynamics, Thermodynamics and Mixed-Layer Processes in the Indian-Ocean. Prog. Oceanogr. 1993, 31, 181-244. [CrossRef]

8. Murtugudde, R.; Busalacchi, A.J. Interannual variability of the dynamics and thermodynamics of the tropical Indian Ocean. J. Clim. 1999, 12, 2300-2326. [CrossRef]

9. Hermes, J.C.; Reason, C.J.C. Annual cycle of the South Indian Ocean (Seychelles-Chagos) thermocline ridge in a regional ocean model. J. Geophys. Res. Ocean. 2008, 113. [CrossRef]

10. Yokoi, T.; Tozuka, T.; Yamagata, T. Seasonal variation of the Seychelles Dome. J. Clim. 2008, 21, 3740-3754. [CrossRef]

11. Han, W.Q.; Meehl, G.A.; Rajagopalan, B.; Fasullo, J.T.; Hu, A.X.; Lin, J.L.; Large, W.G.; Wang, J.W.; Quan, X.W.; Trenary, L.L.; et al. Patterns of Indian Ocean sea-level change in a warming climate. Nat. Geosci. 2010, 3, 546-550. [CrossRef]

12. Timmermann, A.; McGregor, S.; Jin, F.F. Wind Effects on Past and Future Regional Sea Level Trends in the Southern Indo-Pacific. J. Clim. 2010, 23, 4429-4437. [CrossRef]

13. Dunne, R.P.; Barbosa, S.M.; Woodworth, P.L. Contemporary sea level in the Chagos Archipelago, central Indian Ocean. Glob. Planet. Chang. 2012, 82-83, 25-37. [CrossRef]

14. Schwarzkopf, F.U.; Boning, C.W. Contribution of Pacific wind stress to multi-decadal variations in upper-ocean heat content and sea level in the tropical south Indian Ocean. Geophys. Res. Lett. 2011, 38. [CrossRef]

15. Han, W.Q.; Vialard, J.; McPhaden, M.J.; Lee, T.; Masumoto, Y.; Feng, M.; De Ruijter, W.P.M. Indian Ocean Decadal Variability A Review. Bull. Am. Meteorol. Soc. 2014, 95, 1679-1703. [CrossRef]

16. Du, Y.; Xie, S.P. Role of atmospheric adjustments in the tropical Indian Ocean warming during the 20th century in climate models. Geophys. Res. Lett. 2008, 35. [CrossRef]

17. Dong, L.; Zhou, T.J.; Wu, B. Indian Ocean warming during 1958-2004 simulated by a climate system model and its mechanism. Clim. Dyn. 2014, 42, 203-217. [CrossRef]

18. Lee, T.; McPhaden, M.J. Decadal phase change in large-scale sea level and winds in the Indo-Pacific region at the end of the 20th century. Geophys. Res. Lett. 2008, 35. [CrossRef]

19. Thompson, P.R.; Piecuch, C.G.; Merrifield, M.A.; McCreary, J.P.; Firing, E. Forcing of recent decadal variability in the Equatorial and North Indian Ocean. J. Geophys. Res. Ocean. 2016, 121, 6762-6778. [CrossRef]

20. Srinivasu, U.; Ravichandran, M.; Han, W.Q.; Sivareddy, S.; Rahman, H.; Li, Y.L.; Nayak, S. Causes for the reversal of North Indian Ocean decadal sea level trend in recent two decades. Clim. Dyn. 2017, 49, 3887-3904. [CrossRef]

21. Trenary, L.L.; Han, W.Q. Local and remote forcing of decadal sea level and thermocline depth variability in the South Indian Ocean. J. Geophys. Res. Ocean. 2013, 118, 381-398. [CrossRef]

22. Nidheesh, A.G.; Lengaigne, M.; Vialard, J.; Unnikrishnan, A.S.; Dayan, H. Decadal and long-term sea level variability in the tropical Indo-Pacific Ocean. Clim. Dyn. 2013, 41, 381-402. [CrossRef]

23. Feng, M.; McPhaden, M.J.; Xie, S.P.; Hafner, J. La Nina forces unprecedented Leeuwin Current warming in 2011. Sci. Rep. 2013, 3. [CrossRef] [PubMed]

24. Llovel, W.; Fukumori, I.; Meyssignac, B. Depth-dependent temperature change contributions to global mean thermosteric sea level rise from 1960 to 2010. Glob. Planet. Chang. 2013, 101, 113-118. [CrossRef]

25. Wu, Q.R.; Zhang, X.B.; Church, J.A.; Hu, J.Y. Variability and change of sea level and its components in the Indo-Pacific region during the altimetry era. J. Geophys. Res. Ocean. 2017, 122, 1862-1881. [CrossRef]

26. Llovel, W.; Lee, T. Importance and origin of halosteric contribution to sea level change in the southeast Indian Ocean during 2005-2013. Geophys. Res. Lett. 2015, 42, 1148-1157. [CrossRef]

27. Han, W.Q.; Meehl, G.A.; Stammer, D.; Hu, A.X.; Hamlington, B.; Kenigson, J.; Palanisamy, H.; Thompson, P. Spatial Patterns of Sea Level Variability Associated with Natural Internal Climate Modes. Surv. Geophys. 2017, 38, 217-250. [CrossRef]

28. Li, Y.L.; Han, W.Q. Decadal Sea Level Variations in the Indian Ocean Investigated with HYCOM: Roles of Climate Modes, Ocean Internal Variability, and Stochastic Wind Forcing. J. Clim. 2015, 28, 9143-9165. [CrossRef] 
29. Saji, N.H.; Goswami, B.N.; Vinayachandran, P.N.; Yamagata, T. A dipole mode in the tropical Indian Ocean. Nature 1999, 401, 360-363. [CrossRef] [PubMed]

30. Webster, P.J.; Moore, A.M.; Loschnigg, J.P.; Leben, R.R. Coupled ocean-atmosphere dynamics in the Indian Ocean during 1997-98. Nature 1999, 401, 356-360. [CrossRef] [PubMed]

31. Frankcombe, L.M.; McGregor, S.; England, M.H. Robustness of the modes of Indo-Pacific sea level variability. Clim. Dyn. 2015, 45, 1281-1298. [CrossRef]

32. Xie, S.P.; Du, Y.; Huang, G.; Zheng, X.T.; Tokinaga, H.; Hu, K.M.; Liu, Q.Y. Decadal Shift in El Nino Influences on Indo-Western Pacific and East Asian Climate in the 1970s. J. Clim. 2010, 23, 3352-3368. [CrossRef]

33. Han, W.Q.; Meehl, G.A.; Hu, A.X.; Zheng, J.; Kenigson, J.; Vialard, J.; Rajagopalan, B.; Yanto. Decadal Variability of the Indian and Pacific Walker Cells since the 1960s: Do They Covary on Decadal Time Scales? J. Clim. 2017, 30, 8447-8468. [CrossRef]

34. Kumar, K.K.; Rajagopalan, B.; Hoerling, M.; Bates, G.; Cane, M. Unraveling the mystery of Indian monsoon failure during El Nino. Science 2006, 314, 115-119. [CrossRef] [PubMed]

35. Luo, J.-J.; Sasaki, W.; Masumoto, Y. Indian Ocean warming modulates Pacific climate change. Proc. Natl. Acad. Sci. USA 2012, 109, 18701-18706. [CrossRef] [PubMed]

36. Yang, Y.; Xie, S.P.; Wu, L.X.; Kosaka, Y.; Lau, N.C.; Vecchi, G.A. Seasonality and Predictability of the Indian Ocean Dipole Mode: ENSO Forcing and Internal Variability. J. Clim. 2015, 28, 8021-8036. [CrossRef]

37. Wittenberg, A.T.; Rosati, A.; Delworth, T.L.; Vecchi, G.A.; Zeng, F.R. ENSO Modulation: Is It Decadally Predictable? J. Clim. 2014, 27, 2667-2681. [CrossRef]

38. Petris, G.; Petrone, S.; Campagnoli, P. Dynamic linear models. In Dynamic Linear Models with R; Springer: Berlin/Heidelberg, Germany, 2009; pp. 31-84.

39. Goddard, L.; Baethgen, W.; Kirtman, B.; Meehl, G. The urgent need for improved climate models and predictions. Eos Trans. Am. Geophys. Union 2009, 90, 343. [CrossRef]

40. Hurrell, J.; Meehl, G.A.; Bader, D.; Delworth, T.L.; Kirtman, B.; Wielicki, B. A Unified Modeling Approach to Climate System Prediction. Bull. Am. Meteorol. Soc. 2009, 90, 1819-1832. [CrossRef]

41. Meehl, G.A.; Goddard, L.; Murphy, J.; Stouffer, R.J.; Boer, G.; Danabasoglu, G.; Dixon, K.; Giorgetta, M.A.; Greene, A.M.; Hawkins, E.; et al. DECADAL PREDICTION Can It Be Skillful? Bull. Am. Meteorol. Soc. 2009, 90, 1467-1485. [CrossRef]

42. Meehl, G.A.; Goddard, L.; Boer, G.; Burgman, R.; Branstator, G.; Cassou, C.; Corti, S.; Danabasoglu, G.; Doblas-Reyes, F.; Hawkins, E.; et al. DECADAL CLIMATE PREDICTION An Update from the Trenches. Bull. Am. Meteorol. Soc. 2014, 95, 243-267. [CrossRef]

43. Pohlmann, H.; Jungclaus, J.H.; Kohl, A.; Stammer, D.; Marotzke, J. Initializing Decadal Climate Predictions with the GECCO Oceanic Synthesis: Effects on the North Atlantic. J. Clim. 2009, 22, 3926-3938. [CrossRef]

44. Doblas-Reyes, F.J.; Balmaseda, M.A.; Weisheimer, A.; Palmer, T.N. Decadal climate prediction with the European Centre for Medium-Range Weather Forecasts coupled forecast system: Impact of ocean observations. J. Geophys. Res. Atmos. 2011, 116. [CrossRef]

45. Polkova, I.; Kohl, A.; Stammer, D. Predictive Skill for Regional Interannual Steric Sea Level and Mechanisms for Predictability*. J. Clim. 2015, 28, 7407-7419. [CrossRef]

46. Balmaseda, M.A.; Mogensen, K.; Weaver, A.T. Evaluation of the ECMWF ocean reanalysis system ORAS4. Q. J. Roy Meteor. Soc. 2013, 139, 1132-1161. [CrossRef]

47. Carton, J.A.; Giese, B.S. A reanalysis of ocean climate using Simple Ocean Data Assimilation (SODA). Mon. Weather Rev. 2008, 136, 2999-3017. [CrossRef]

48. Vidard, A.; Balmaseda, M.; Anderson, D. Assimilation of Altimeter Data in the ECMWF Ocean Analysis System 3. Mon. Weather Rev. 2009, 137, 1393-1408. [CrossRef]

49. Nidheesh, A.G.; Lengaigne, M.; Vialard, J.; Izumo, T.; Unnikrishnan, A.S.; Meyssignac, B.; Hamlington, B.; Montegut, C.D. Robustness of observation-based decadal sea level variability in the Indo-Pacific Ocean. Geophys. Res. Lett. 2017, 44, 7391-7400. [CrossRef]

50. Levitus, S.; Antonov, J.I.; Boyer, T.P.; Baranova, O.K.; Garcia, H.E.; Locarnini, R.A.; Mishonov, A.V.; Reagan, J.R.; Seidov, D.; Yarosh, E.S.; et al. World ocean heat content and thermosteric sea level change (0-2000 m), 1955-2010. Geophys. Res. Lett. 2012, 39. [CrossRef]

51. Ishii, M.; Kimoto, M.; Sakamoto, K.; Iwasaki, S.I. Steric sea level changes estimated from historical ocean subsurface temperature and salinity analyses. J. Oceanogr. 2006, 62, 155-170. [CrossRef] 
52. Ducet, N.; Le Traon, P.Y.; Reverdin, G. Global high-resolution mapping of ocean circulation from TOPEX/Poseidon and ERS-1 and-2. J. Geophys. Res. Ocean. 2000, 105, 19477-19498. [CrossRef]

53. Rio, M.H.; Guinehut, S.; Larnicol, G. New CNES-CLS09 global mean dynamic topography computed from the combination of GRACE data, altimetry, and in situ measurements. J. Geophys. Res. Ocean. 2011, 116. [CrossRef]

54. Kobayashi, S.; Ota, Y.; Harada, Y.; Ebita, A.; Moriya, M.; Onoda, H.; Onogi, K.; Kamahori, H.; Kobayashi, C.; Endo, H.; et al. The JRA-55 Reanalysis: General Specifications and Basic Characteristics. J. Meteorol. Soc. Jpn. 2015, 93, 5-48. [CrossRef]

55. Atlas, R.; Hoffman, R.N.; Ardizzone, J.; Leidner, S.M.; Jusem, J.C.; Smith, D.K.; Gombos, D. A Cross-Calibrated Multiplatform Ocean Surface Wind Velocity Product for Meteorological and Oceanographic Applications. Bull. Am. Meteorol. Soc. 2011, 92, 157. [CrossRef]

56. Liebmann, B.; Smith, C.A. Description of a complete (interpolated) outgoing longwave radiation dataset. Bull. Am. Meteorol. Soc. 1996, 77, 1275-1277.

57. Adler, R.F.; Gu, G.J.; Sapiano, M.; Wang, J.J.; Huffman, G.J. Global Precipitation: Means, Variations and Trends During the Satellite Era (1979-2014). Surv. Geophys. 2017, 38, 679-699. [CrossRef]

58. Duchon, C.E. Lanczos Filtering in One and 2 Dimensions. J. Appl. Meteorol. 1979, 18, 1016-1022. [CrossRef]

59. Deser, C.; Phillips, A.S.; Tomas, R.A.; Okumura, Y.M.; Alexander, M.A.; Capotondi, A.; Scott, J.D.; Kwon, Y.O.; Ohba, M. ENSO and Pacific Decadal Variability in the Community Climate System Model Version 4. J. Clim. 2012, 25, 2622-2651. [CrossRef]

60. Meyssignac, B.; Becker, M.; Llovel, W.; Cazenave, A. An Assessment of Two-Dimensional Past Sea Level Reconstructions Over 1950-2009 Based on Tide-Gauge Data and Different Input Sea Level Grids. Surv. Geophys. 2012, 33, 945-972. [CrossRef]

61. Han, W.Q.; Meehl, G.A.; Hu, A.X.; Alexander, M.A.; Yamagata, T.; Yuan, D.L.; Ishii, M.; Pegion, P.; Zheng, J.; Hamlington, B.D.; et al. Intensification of decadal and multi-decadal sea level variability in the western tropical Pacific during recent decades. Clim. Dyn. 2014, 43, 1357-1379. [CrossRef]

62. Kay, J.E.; Deser, C.; Phillips, A.; Mai, A.; Hannay, C.; Strand, G.; Arblaster, J.M.; Bates, S.C.; Danabasoglu, G.; Edwards, J.; et al. The Community Earth System Model (Cesm) Large Ensemble Project A Community Resource for Studying Climate Change in the Presence of Internal Climate Variability. Bull. Am. Meteorol. Soc. 2015, 96, 1333-1349. [CrossRef]

63. Bittner, M.; Schmidt, H.; Timmreck, C.; Sienz, F. Using a large ensemble of simulations to assess the Northern Hemisphere stratospheric dynamical response to tropical volcanic eruptions and its uncertainty. Geophys. Res. Lett. 2016, 43, 9324-9332. [CrossRef]

64. Song, Q.; Vecchi, G.A.; Rosati, A.J. Indian Ocean variability in the GFDL coupled climate model. J. Clim. 2007, 20, 2895-2916. [CrossRef]

65. Tozuka, T.; Luo, J.J.; Masson, S.; Yamagata, T. Decadal modulations of the Indian Ocean dipole in the SINTEX-F1 coupled GCM. J. Clim. 2007, 20, 2881-2894. [CrossRef]

66. Zhang, X.B.; Church, J.A. Sea level trends, interannual and decadal variability in the Pacific Ocean. Geophys. Res. Lett. 2012, 39. [CrossRef]

67. Rayner, N.A.; Brohan, P.; Parker, D.E.; Folland, C.K.; Kennedy, J.J.; Vanicek, M.; Ansell, T.J.; Tett, S.F.B. Improved analyses of changes and uncertainties in sea surface temperature measured in situ since the mid-nineteenth century: The HadSST2 dataset. J. Clim. 2006, 19, 446-469. [CrossRef]

68. Parthasarathy, B.; Munot, A.A.; Kothawale, D.R. All-India Monthly and Seasonal Rainfall Series-1871-1993. Theor. Appl. Climatol. 1994, 49, 217-224. [CrossRef]

69. Klein, S.A.; Soden, B.J.; Lau, N.C. Remote sea surface temperature variations during ENSO: Evidence for a tropical atmospheric bridge. J. Clim. 1999, 12, 917-932. [CrossRef]

70. Dong, L.; Mcphaden, M.J. Why Has the Relationship between Indian and Pacific Ocean Decadal Variability Changed in Recent Decades? J. Clim. 2017, 30, 1971-1983. [CrossRef]

71. Zhang, L.; Han, W.Q.; Sienz, F. Unraveling Causes for the Changing Behavior of the Tropical Indian Ocean in the Past Few Decades. J. Clim. 2018, 31, 2377-2388. [CrossRef]

72. Hamlington, B.D.; Strassburg, M.W.; Leben, R.R.; Han, W.; Nerem, R.S.; Kim, K.Y. Uncovering an anthropogenic sea-level rise signal in the Pacific Ocean. Nat. Clim. Chang. 2014, 4, 782-785. [CrossRef] 
73. Loschnigg, J.; Meehl, G.A.; Webster, P.J.; Arblaster, J.M.; Compo, G.P. The Asian monsoon, the tropospheric biennial oscillation, and the Indian Ocean zonal mode in the NCAR CSM. J. Clim. 2003, 16, 1617-1642. [CrossRef]

74. Meehl, G.A.; Arblaster, J.M.; Loschnigg, J. Coupled ocean-atmosphere dynamical processes in the tropical Indian and Pacific Oceans and the TBO. J. Clim. 2003, 16, 2138-2158. [CrossRef]

75. Izumo, T.; Vialard, J.; Lengaigne, M.; Montegut, C.D.; Behera, S.K.; Luo, J.J.; Cravatte, S.; Masson, S.; Yamagata, T. Influence of the state of the Indian Ocean Dipole on the following year's El Nino. Nat. Geosci. 2010, 3, 168-172. [CrossRef]

76. Krishnaswamy, J.; Vaidyanathan, S.; Rajagopalan, B.; Bonell, M.; Sankaran, M.; Bhalla, R.S.; Badiger, S. Non-stationary and non-linear influence of ENSO and Indian Ocean Dipole on the variability of Indian monsoon rainfall and extreme rain events. Clim. Dyn. 2015, 45, 175-184. [CrossRef]

77. Yanto; Rajagopalan, B.; Zagona, E. Space-time variability of Indonesian rainfall at inter-annual and multi-decadal time scales. Clim. Dyn. 2016, 47, 2975-2989. [CrossRef]

78. Han, W.Q.; McCreary, J.P.; Anderson, D.L.T.; Mariano, A.J. Dynamics of the eastern surface jets in the equatorial Indian Ocean. J. Phys. Oceanogr. 1999, 29, 2191-2209. [CrossRef]

79. Han, W.Q.; McCreary, J.P.; Masumoto, Y.; Vialard, J.; Duncan, B. Basin Resonances in the Equatorial Indian Ocean. J. Phys. Oceanogr. 2011, 41, 1252-1270. [CrossRef]

80. Shankar, D.; Aparna, S.G.; McCreary, J.P.; Suresh, I.; Neetu, S.; Durand, F.; Shenoi, S.S.C.; Al Saafani, M.A. Minima of interannual sea-level variability in the Indian Ocean. Prog. Oceanogr. 2010, 84, 225-241. [CrossRef]

81. Han, W.Q.; McCreary, J.P. Modeling salinity distributions in the Indian Ocean. J. Geophys. Res. Ocean. 2001, 106, 859-877. [CrossRef]

82. Hamlington, B.D.; Leben, R.R.; Nerem, R.S.; Han, W.; Kim, K.Y. Reconstructing sea level using cyclostationary empirical orthogonal functions. J. Geophys. Res. Ocean. 2011, 116. [CrossRef]

83. Pfeffer, J.; Allemand, P. The key role of vertical land motions in coastal sea level variations: A global synthesis of multisatellite altimetry, tide gauge data and GPS measurements. Earth Planet. Sci. Lett. 2016, 439, 39-47. [CrossRef]

84. Roemmich, D.; Gilson, J. The 2004-2008 mean and annual cycle of temperature, salinity, and steric height in the global ocean from the Argo Program. Prog. Oceanogr. 2009, 82, 81-100. [CrossRef]

85. Von Schuckmann, K.; Gaillard, F.; Le Traon, P.Y. Global hydrographic variability patterns during 2003-2008. J. Geophys. Res. Ocean. 2009, 114. [CrossRef]

86. Hosoda, S.; Suga, T.; Shikama, N.; Mizuno, K. Global Surface Layer Salinity Change Detected by Argo and Its Implication for Hydrological Cycle Intensification. J. Oceanogr. 2009, 65, 579-586. [CrossRef]

87. Durack, P.J.; Wijffels, S.E. Fifty-Year Trends in Global Ocean Salinities and Their Relationship to Broad-Scale Warming. J. Clim. 2010, 23, 4342-4362. [CrossRef]

88. Helm, K.P.; Bindoff, N.L.; Church, J.A. Changes in the global hydrological-cycle inferred from ocean salinity. Geophys. Res. Lett. 2010, 37. [CrossRef]

89. Church, J.A.; White, N.J. Sea-Level Rise from the Late 19th to the Early 21st Century. Surv. Geophys. 2011, 32, 585-602. [CrossRef]

90. Bradshaw, E.; Richards, L.; Thorkild, A. Sea level data archaeology and the Global Sea Level Observing System (GLOSS). GeoResJ 2015, 6, 9-16. [CrossRef]

91. Gent, P.R.; Danabasoglu, G.; Donner, L.J.; Holland, M.M.; Hunke, E.C.; Jayne, S.R.; Lawrence, D.M.; Neale, R.B.; Rasch, P.J.; Vertenstein, M.; et al. The Community Climate System Model Version 4. J. Clim. 2011, 24, 4973-4991. [CrossRef]

92. Cai, W.J.; Cowan, T. Why is the amplitude of the Indian Ocean Dipole overly large in CMIP3 and CMIP5 climate models? Geophys. Res. Lett. 2013, 40, 1200-1205. [CrossRef]

93. Weller, E.; Cai, W.J. Realism of the Indian Ocean Dipole in CMIP5 Models: The Implications for Climate Projections. J. Clim. 2013, 26, 6649-6659. [CrossRef]

94. Storto, A.; Masina, S.; Balmaseda, M.; Guinehut, S.; Xue, Y.; Szekely, T.; Fukumori, I.; Forget, G.; Chang, Y.S.; Good, S.A.; et al. Steric sea level variability (1993-2010) in an ensemble of ocean reanalyses and objective analyses. Clim. Dyn. 2017, 49, 709-729. [CrossRef]

95. Slangen, A.B.A.; Meyssignac, B.; Agosta, C.; Champollion, N.; Church, J.A.; Fettweis, X.; Ligtenberg, S.R.M.; Marzeion, B.; Melet, A.; Palmer, M.D.; et al. Evaluating Model Simulations of Twentieth-Century Sea Level Rise. Part I: Global Mean Sea Level Change. J. Clim. 2017, 30, 8539-8563. [CrossRef] 
96. Meyssignac, B.; Slangen, A.B.A.; Melet, A.; Church, J.A.; Fettweis, X.; Marzeion, B.; Agosta, C.; Ligtenberg, S.R.M.; Spada, G.; Richter, K.; et al. Evaluating Model Simulations of Twentieth-Century Sea-Level Rise. Part II: Regional Sea-Level Changes. J. Clim. 2017, 30, 8565-8593. [CrossRef]

97. Han, W.Q.; Webster, P.J. Forcing mechanisms of sea level interannual variability in the Bay of Bengal. J. Phys. Oceanogr. 2002, 32, 216-239. [CrossRef]

98. Furue, R.; McCreary, J.P.; Benthuysen, J.; Phillips, H.E.; Bindoff, N.L. Dynamics of the Leeuwin Current: Part 1. Coastal flows in an inviscid, variable-density, layer model. Dyn. Atmos. Ocean. 2013, 63, 24-59. [CrossRef]

(C) 2018 by the authors. Licensee MDPI, Basel, Switzerland. This article is an open access article distributed under the terms and conditions of the Creative Commons Attribution (CC BY) license (http://creativecommons.org/licenses/by/4.0/). 